\title{
CARACTERIZAÇÃO FÍSICA, QUÍMICA, MINERALÓGICA E MICROMORFOLÓGICA DE HORIZONTES COESOS E FRAGIPÃS DE SOLOS VERMELHOS E AMARELOS DO AMBIENTE TABULEIROS COSTEIROS ${ }^{(1)}$
}

\author{
Marcelo Metri Corrêa ${ }^{(2)}$, João Carlos Ker ${ }^{(3)}$, Vidal Barrón ${ }^{(4)}$, José \\ Torrent $^{(4)}$, Nilton Curi ${ }^{(5)} \&$ Thiago C. Pereira Torres ${ }^{(6)}$
}

\begin{abstract}
RESUMO
O objetivo do presente trabalho foi avaliar física, química, mineralógica e micromorfologicamente solos vermelhos, amarelos e acinzentados coesos em três toposseqüências na região dos Tabuleiros Costeiros do sul da Bahia e norte do Espírito Santo, desenvolvidos a partir de sedimentos do Grupo Barreiras ou de rochas gnáissicas do Pré-Cambriano, assim como os possíveis mecanismos físicos e, ou, mineralógicos que promovem a coesão dos solos e formação de fragipãs. Para isso, foram realizadas análises físicas; determinadas a relação argila fina/ argila grossa, superfícies específicas por BET- $\mathrm{N}_{2}$ e adsorção de vapor de água, susceptibilidade magnética; e analisados os constituintes por microscopia eletrônica de varredura e micromorfologia em lâminas delgadas. As análises físicas e micromorfológica indicam que a gênese dos horizontes coesos deve-se ao maior conteúdo de argilas muito finas, principalmente menores que $0,2 \mu \mathrm{m}$, translocadas entre horizontes ou dentro do mesmo horizonte como argila dispersa. A maior coesão observada para o Argissolo Amarelo localizado em clima mais seco, em relação àqueles em clima mais úmido, pode ser devido à sua granulometria menos argilosa e maior quantidade de feições de iluviação de argila.
\end{abstract}

Termos de indexação: coesão, fragipã, Grupo Barreiras.

\footnotetext{
(1) Trabalho da Tese de Doutorado do primeiro autor, em Solos e Nutrição de Plantas pela Universidade Federal de Viçosa - UFV. Resumo expandido publicado no XXX Congresso Brasileiro de Ciência do Solo. Recebido para publicação em outubro de 2006 e aprovado em setembro de 2007.

${ }^{(2)}$ Professor da Unidade Acadêmica de Garanhuns, Universidade Federal Rural de Pernambuco - UFRPE. Rua Dom Manoel de Medeiros s/n, Dois Irmãos, CEP 52171-900 Recife (PE). Bolsita PDEE/CAPES. E-mail: marcelometri@yahoo.com

${ }^{(3)}$ Professor do Departamento de Solos, Universidade Federal de Viçosa - UFV. Av. PH Rolfs s/n, CEP 36570-000 Viçosa (MG). E-mail: jcker@ufv.br

(4) Professor do Departamento de Ciencias y Recursos Agricolas y Florestales, Universidad de Córdoba - UCO. Edificio Paraninfo - Campus de Rabanales, Coórdoba-Espanha. E-mail: vidal@uco.es

(5) Professor do Departamento de Solos, Departamento de Ciência do Solo da Universidade Federal de Lavras - DCS/UFLA. Caixa Postal 37, CEP 37200-000 Lavras (MG). E-mail: niltcuri@ufla.br

(6) Mestrando do Departamento de Solos, UFV. E-mail: torresthiago@yahoo.com.br
} 


\title{
SUMMARY: PHYSICAL, CHEMICAL, MINERALOGICALANDMICROMORPHO- LOGICAL CHARACTERIZATION OF COHESIVE HORIZONS AND FRAGIPANS OF RED AND YELLOW SOILS OF COASTAL TABLELANDS
}

\begin{abstract}
The objective of this study was to evaluate the physical, chemical, mineralogical and micromorphological characteristics of cohesive red, yellow and grayish soils in a toposequence of the Coastal Tablelands region in southern Bahia and northern Espirito Santo states. It was also sought to understand the mechanisms promoting their cohesion and fragipan formation. Therefore, the routine physical analyses, determination of the coarse clay/fine clay ratio, specific surface by BET- $N_{2}$ and water vapor adsorption, magnetic susceptibility, scanning-electron microscopy analyses and the micromorphology of thin plates were carried out. Physical and micromorphological analyses indicated that the high content of very fine clays, especially those smaller than $0.2 \mu \mathrm{m}$, translocated among horizons or within a same horizon as dispersed clay, were responsible for the genesis of the cohesive horizons. The higher cohesion observed in the Yellow Argisol (Ultisol) found in a drier climate, compared to those in a more humid climate could be due to the less clayey granulometry and a larger amount of clay illuviation features.
\end{abstract}

Index terms: Barreiras Group; cohesion; fragipan.

\section{INTRODUÇÃO}

Os solos da região dos Tabuleiros Costeiros são predominantemente Latossolos Amarelos e Argissolos Amarelos, encontrando-se, também, em menor expressão, os Espodossolos, Argissolos Acinzentados, Neossolos Quartzarênicos e Plintossolos (Embrapa, 1995; Jacomine, 1996). Contudo, alguns trabalhos relatam a presença de solos vermelhos na região dos Tabuleiros Costeiros do Estado da Bahia (Embrapa, 1995; Moreau, 2001).

Todos os solos da região possuem fortes limitações agrícolas naturais, como, por exemplo, baixa fertilidade e baixa reserva em nutrientes. Além disso, podem apresentar horizontes subsuperficiais endurecidos, que reduzem a profundidade efetiva do solo e, conseqüentemente, o desenvolvimento do sistema radicular. O endurecimento é normalmente constatado no horizonte A e topo do B dos LA e PA, quando secos, sendo sua dureza tão expressiva que mereceu a adoção da adjetivação "coeso" para estes solos (Brasil, 1972, 1983; Embrapa, 1977, 1978).

O caráter coeso, ainda que de definição pouco consistente, foi e continua sendo utilizado na estruturação taxonômica de Latossolos no atual Sistema Brasileiro de Classificação de Solos (SiBCS) (Embrapa, 1999); principalmente os Amarelos desenvolvidos de sedimentos do Grupo Barreiras. Tem sido constatado também solos vermelhos coesos na região dos Tabuleiros do sul da Bahia, norte do Espírito Santo e nordeste de Minas Gerais, nem sempre desenvolvidos sobre sedimentos do Grupo Barreiras.

Vários foram os trabalhos direcionados ao estudo da gênese dos horizontes coesos de Latossolos e Argissolos Amarelos no Brasil (Achá-Panoso, 1976; UFV, 1984; Anjos, 1985; Fonseca, 1986; Ferreira, 1988;
Meireles \& Ribeiro, 1995; Ribeiro, 1998; Moreau, 2001). Entretanto, entre os resultados encontrados, muitos mostram-se contraditórios e poucos conclusivos. Além disso, muitos foram realizados com horizontes nãotípicos, tendo, como conseqüência, a geração de dados não representativos. Isso vale tanto no que se refere à gênese desses solos, como também na aplicação direta e imediata do conhecimento adquirido no direcionamento de práticas de preparo do solo, particularmente aquelas relacionadas à profundidade de subsolagem e necessidade de adaptação de equipamentos agrícolas indispensáveis ao rompimento da camada coesa (ou parte dela). O conhecimento correto sobre os horizontes coesos pode permitir implantação mais racional e maior desenvolvimento de culturas nas áreas de ocorrência de solos dessa natureza, como eucalipto (BA e ES), citros (SE) e canade-açúcar (PE, AL e RJ).

Somando a tudo isso, merecem destaque os poucos trabalhos que contemplam estudos concernentes aos fragipãs, duripãs, ortsteins e horizontes plácicos, muito comuns nas áreas mais deprimidas dentro do domínio dos LA e PA coesos. Essas áreas, popularmente referenciadas como "mussunungas" (solos arenosos que acumulam água), ocupam áreas expressivas no sul da Bahia e no norte do Espírito Santo e, invariavelmente, vêm sendo restringidas para exploração agrícola, sobretudo com eucalipto.

O presente trabalho foi conduzido a fim de avaliar física, química, mineralógica e micromorfologicamente os solos vermelhos e amarelos coesos (Argissolos) e Espodossolos, em três toposseqüências na região dos Tabuleiros Costeiros do sul da Bahia e norte do Espírito Santo, bem como identificar os possíveis mecanismos físicos e, ou, mineralógicos, que promovem a coesão dos solos e a ocorrência de fragipãs. 


\section{MATERIAL E MÉTODOS}

Foram descritos e coletados nove perfis de solo, conforme Lemos \& Santos (1996), classificados como Argissolo Vermelho latossólico (dois perfis), Argissolo Amarelo latossólico (um perfil), Argissolo Amarelo (três perfis), Argissolo Acinzentado (um perfil) e Espodossolo (dois perfis), em área de elevada precipitação e sem déficit hídrico pronunciado, no município de Teixeiras de Freitas-BA (Figura 1). Para avaliação do possível efeito de ciclos de umedecimento e secagem na coesão, foi coletado, ainda, um perfil de Argissolo Amarelo em área bem mais seca, no município de Mucurici-ES.

De acordo com a classificação de Köppen, o clima da região de Teixeira de Freitas (sul da Bahia) é do tipo Am, tropical chuvoso, de monção, com inverno seco e mês mais frio com precipitação inferior a $60 \mathrm{~mm}$ e temperatura superior a $18{ }^{\circ} \mathrm{C}$. Em Mucurici (norte de Espírito Santo), é do tipo Aw, caracterizado pela presença de um período seco mais longo que a área anterior, com temperatura superior a $20^{\circ} \mathrm{C}$ (Siqueira et al., 2004).

A área está inserida no domínio dos Tabuleiros Costeiros, caracterizada por sedimentos do Cenozóico do Grupo Barreiras, constituídos de materiais argilosos ou argilo-arenosos com espessura variada em conformidade com as ondulações do substrato rochoso (biotita e, ou, hornblenda-granada gnaisses do Complexo Paraíba do Sul-Pré-Cambriano) que ocasionamente aflora, influenciando as formas do modelado (DNPM, 1984; Silva et al., 1987).
Foram determinadas a composição granulométrica, a argila dispersa em água, a densidade do solo (método do torrão parafinado) e de partículas e calculados o grau de floculação e a porosidade total, todos segundo os métodos constantes em Embrapa (1997).

Para determinação da relação argila fina/argila grossa, efetuou-se a remoção dos óxidos de ferro de $2 \mathrm{~g}$ de TFSA, por meio de cinco extrações sucessivas com ditionito-citrato-bicarbonado à temperatura ambiente (Schwertmann \& Carlson, 1994). A dispersão do material desferrificado foi realizada com solução com $\mathrm{NaOH} 0,01 \mathrm{~mol} \mathrm{~L}^{-1}$. Em seguida, a fração coloidal foi separada por meio de sucessivas sifonações e agitações (princípio da decantação da lei de Stokes), até obtenção de uma suspensão translúcida. Dessa forma, foi obtida a argila total desferrificada, que foi separada em argila grossa (entre 2 e $0,2 \mu \mathrm{m}$ ) e argila fina (menor que $0,2 \mu \mathrm{m}$ ) por centrifugação (Jackson, 1969). As centrifugações (média de 20) foram realizadas até que a suspensão se mostrasse totalmente translúcida. Entre cada seção de centrifugação, as amostras eram novamente agitadas e dispersas, utilizando-se ultrasom e solução de $\mathrm{NaOH} 0,01 \mathrm{~mol} \mathrm{~L}^{-1}$, respectivamente.

A superfície específica (SE) da TFSA foi determinada por meio do método de sorção de vapor de água (Quirk, 1955). A SE também foi determinada na fração argila fina, desferrificada e tratada para eliminação da matéria orgânica, de alguns horizontes de perfis selecionados. Nesse caso, foi utilizado o Surface Area Analyzers, modelo ASAP 2010 (Micromeritics ${ }^{\circledR}$ ), sendo a determinação conduzida em atmosfera de $\mathrm{N}$ (adsorbato).

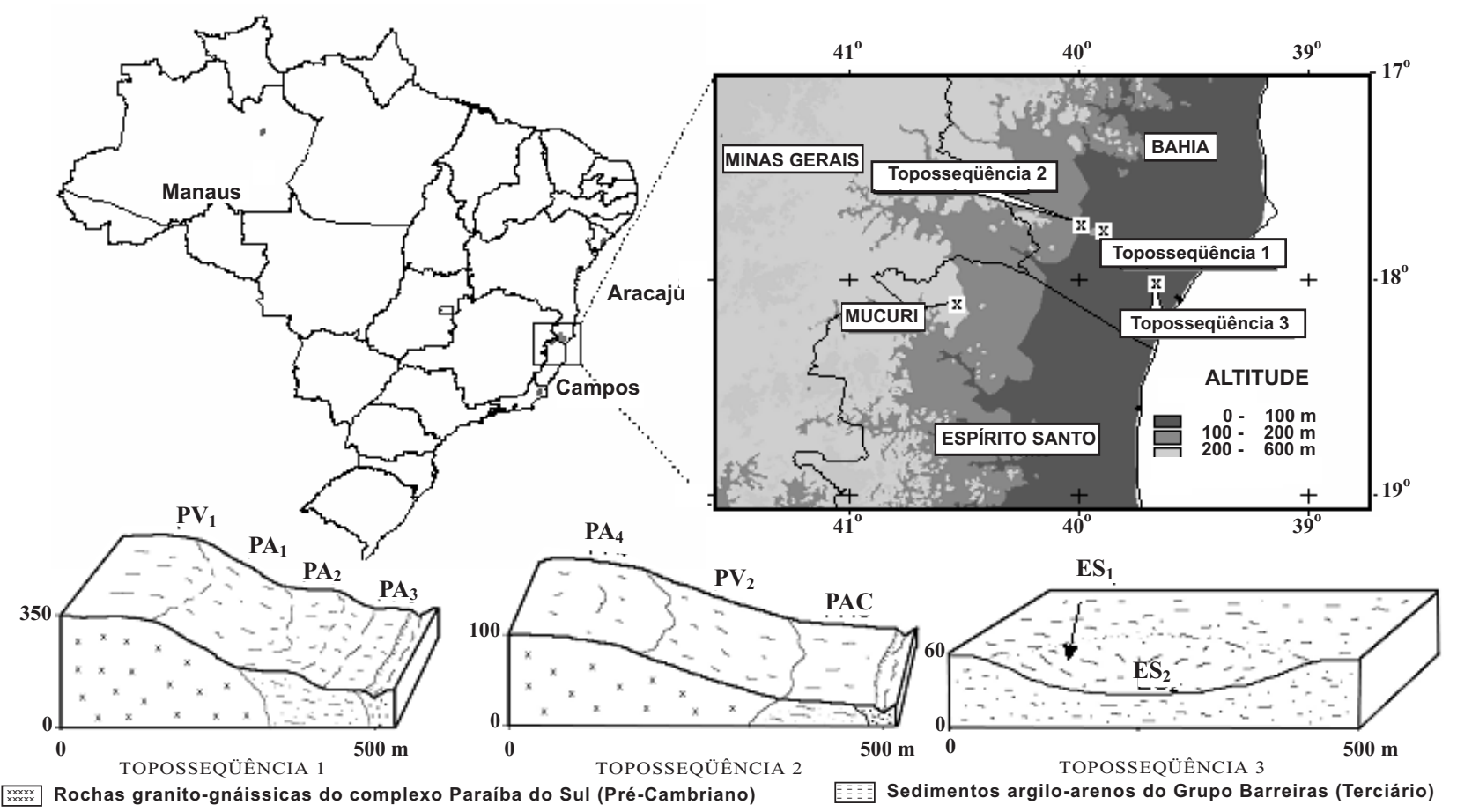

Sedimentos argilosos recentes (Holoceno)

Figura 1. Localização dos perfis coletados e representação de suas toposseqüências. 
Com relação às análises químicas, procedeu-se à determinação de: $\mathrm{pH}$ em água e em KCl $1 \mathrm{~mol} \mathrm{~L}^{-1}$; C orgânico total, pelo método de Yoemans \& Bremner (1988); $\mathrm{Na}^{+}$e $\mathrm{K}^{+}$, por fotometria de chama, após extração com $\mathrm{HCl} 0,05 \mathrm{~mol} \mathrm{~L}^{-1}$; e Ca ${ }^{2+}, \mathrm{Mg}^{2+} \mathrm{e} \mathrm{Al}^{3+}$, por extração com KCl $1 \mathrm{~mol} \mathrm{~L}^{-1}$ e determinação por espectrofotometria de absorção atômica. A acidez potencial $(\mathrm{Al}+\mathrm{H})$ foi avaliada por extração com acetato de Ca $0,5 \mathrm{~mol} \mathrm{~L}^{-1}$ a pH 7,0. Todas as análises foram baseadas no método constante em Embrapa (1997).

Os minerais da TFSA foram identificados por difratometria de raios X(DRX), em aparelho Siemmens D-5000 com radiação $\mathrm{CoK} \alpha$, dispondo de monocromador de grafite e operado a $40 \mathrm{kV}$ e $25 \mathrm{~mA}$. $\mathrm{O}$ conjunto foi montado em suporte de $\mathrm{Al}$, após pressão suave da amostra sobre papel rugoso, de forma a minimizar a orientação preferencial das partículas. As irradiações promovidas variaram de 4 a $60^{\circ} 2 \theta$, com intervalo de $0,05^{\circ} 2 \theta$ a cada oito segundos.

Para avaliação da organização natural das partículas, estudaram-se pequenos torrões de solo indeformados, em microscopia eletrônica de varredura. A observação foi realizada em baixo vácuo, sem impregnação, em aparelho Fei Quanta 200.

As amostras de horizontes coesos e não-coesos de um mesmo perfil foram coletadas, secas em estufa com circulação forçada de ar a $35^{\circ} \mathrm{C}$ e, posteriormente, impregnadas com resina de poliéster. As feições micropedológicas foram analisadas, de acordo com Fitzpatrick (1993).

\section{RESULTADOS E DISCUSSÃO}

\section{Caracterização morfológica}

As características morfológicas são, resumidamente, descritas no quadro 1. Foram observadas variações em cor, estrutura e consistência entre os horizontes e entre os solos estudados. Os Argissolos apresentaram cores amareladas (matizes $10 \mathrm{YR}$ e $7,5 \mathrm{YR}$ ) e

\section{Quadro 1. Características morfológicas dos solos estudados}

\begin{tabular}{|c|c|c|c|c|c|c|c|}
\hline \multirow{2}{*}{ Horizonte } & \multirow{2}{*}{ Profundidade } & \multirow{2}{*}{ Cor (úmido) } & \multirow{2}{*}{ Estrutura } & \multicolumn{3}{|c|}{ Consistência } & \multirow[b]{2}{*}{ Trans. } \\
\hline & & & & Seca & Úmida & Molhada & \\
\hline \multicolumn{8}{|c|}{ ( } \\
\hline \multicolumn{8}{|c|}{$\begin{array}{c}\text { Toposseqüência } 1 \\
\text { Argissolo Vermelho eutrófico latossólico }\left(\mathrm{PV}_{1}\right)\end{array}$} \\
\hline A & $0-12$ & $5 \mathrm{YR} 3 / 4$ & 3PMBls Bla & - & $\mathrm{Fi}$ & $\mathrm{Pl} \mathrm{Pe}$ & $\mathrm{cp}$ \\
\hline BA & $12-24$ & $3,5 \mathrm{YR} 4 / 6$ & $12 \mathrm{P} \mathrm{M} \mathrm{Bls}$ & - & $\mathrm{Fi}$ & $\mathrm{Pl} \mathrm{Pe}$ & gp \\
\hline Bt1 & $24-56$ & $2,5 \mathrm{YR} 4 / 8$ & $12 \mathrm{P} \mathrm{M} \mathrm{Bls}$ & - & $\mathrm{Fi}$ & $\mathrm{Pl} \mathrm{Pe}$ & $d p$ \\
\hline Bt2 & $56-97$ & $2,5 \mathrm{YR} 4 / 8$ & $1 \mathrm{M} \mathrm{Bls}$ & - & $\mathrm{MFr}$ & $\mathrm{Pl} \mathrm{Pe}$ & $\mathrm{dp}$ \\
\hline Bt3 & $97-170+$ & $2,5 \mathrm{YR} 4 / 8$ & $1 \mathrm{M} \mathrm{Bls}$ & - & $\mathrm{MFr}$ & $\mathrm{Pl} \mathrm{Pe}$ & - \\
\hline \multicolumn{8}{|c|}{ Argissolo Amarelo eutrófico $\left(\mathrm{PA}_{1}\right)$} \\
\hline A & $0-5$ & 10YR $2 / 1$ & Gs $2 \mathrm{M} \mathrm{Gr}$ & - & $\mathrm{MFr}$ & LgPl LgPe & $\mathrm{cp}$ \\
\hline $\mathrm{AB}$ & $5-19$ & 10YR 5/4 & $1 \mathrm{P} \mathrm{Bls}$ & - & $\mathrm{Fr}$ & LgPl LgPe & gp \\
\hline BA & $19-33$ & $10 \mathrm{YR} 5 / 6$ & $12 \mathrm{P} \mathrm{M} \mathrm{Bls}$ & - & $\mathrm{Fi}$ & $\mathrm{Pl} \mathrm{Pe}$ & gp \\
\hline Bt1 & $33-70$ & $10 \mathrm{YR} 6 / 8$ & $12 \mathrm{P} \mathrm{M} \mathrm{Bls}$ & - & $\mathrm{Fi}$ & $\mathrm{MtPl} \mathrm{MtPe}$ & $\mathrm{dp}$ \\
\hline $\mathrm{Bt} 2$ & $70-110$ & 10YR $6 / 8$ & $12 \mathrm{P} \mathrm{M} \mathrm{Bls}$ & - & $\mathrm{Fi}$ & $\mathrm{Pl} \mathrm{Pe}$ & $\mathrm{dp}$ \\
\hline Bt3 & $110-150+$ & 10YR $6 / 8$ & $12 \mathrm{P} \mathrm{M} \mathrm{Bls}$ & - & $\mathrm{Fi}$ & $\mathrm{Pl} \mathrm{Pe}$ & \\
\hline \multicolumn{8}{|c|}{ Argissolo Amarelo distrófico $\left(\mathrm{PA}_{2}\right)$} \\
\hline Ap1 & $0-7$ & 10YR $3 / 1$ & Gs $2 \mathrm{G} \mathrm{Gr}$ & - & - & $\tilde{n} \mathrm{Pl} \tilde{\mathrm{nPe}}$ & gp \\
\hline Ap2 & $7-17$ & $10 \mathrm{YR} 3 / 2$ & $12 \mathrm{P} \mathrm{Bls}$ & - & - & $\tilde{n} \mathrm{Pl} \operatorname{LgPe}$ & $\mathrm{cp}$ \\
\hline BA & $17-41$ & 2,5 YR $5 / 4$ & $12 \mathrm{P} \mathrm{M} \mathrm{Bls}$ & - & - & $\mathrm{LgPl} \mathrm{LgPe}$ & gp \\
\hline Bt1 & $41-75$ & $10 \mathrm{YR} 5 / 8$ & $1 \mathrm{P} \mathrm{M} \mathrm{Bls}$ & - & - & $\mathrm{Pl} \mathrm{Pe}$ & $\mathrm{dp}$ \\
\hline $\mathrm{Bt} 2$ & $75-124$ & 10YR $5 / 8$ & $1 \mathrm{P} \mathrm{M} \mathrm{Bls}$ & - & - & $\mathrm{Pl} \mathrm{Pe}$ & $d p$ \\
\hline Bt3 & $124-150+$ & $10 \mathrm{YR} 5 / 8$ & $1 \mathrm{P} \mathrm{M} \mathrm{Bls}$ & - & - & $\mathrm{Pl} \mathrm{Pe}$ & - \\
\hline \multicolumn{8}{|c|}{ Argissolo Amarelo distrófico $\left(\mathrm{PA}_{3}\right)$} \\
\hline Ap & $0-12$ & $10 \mathrm{YR} 3 / 2$ & Gs 2 P M Gr Bls & - & Fr & $\tilde{n} \mathrm{Pl} \tilde{\mathrm{n} P e}$ & $\mathrm{cp}$ \\
\hline $\mathrm{AB}$ & $12-25$ & 10YR $5 / 3$ & $1 \mathrm{P} \mathrm{Bls}$ & - & MFr & $\tilde{n} \mathrm{Pl} \tilde{\mathrm{nPe}}$ & gp \\
\hline $\mathrm{BA}$ & $25-43$ & $10 \mathrm{YR} 5,5 / 4$ & $1 \mathrm{P} \mathrm{M} \mathrm{Bls}$ & - & MFr & LgPl LgPe & $\mathrm{dp}$ \\
\hline Bt1 & $43-75$ & 10YR 6/4 & $1 \mathrm{P} \mathrm{M} \mathrm{Bls}$ & - & $\mathrm{Fr}$ & LgPl LgPe & ap \\
\hline $\mathrm{Cx} 1$ & $75-90$ & 10YR 6/6 & Ma coesa & - & $\mathrm{Fr}$ & LgPl LgPe & ap \\
\hline Cxf2 & $90-102$ & $\begin{array}{l}\text { 10YR } 6 / 6 ; 2,5 \text { YR } 5 / 8 \\
5 \text { YR } 4 / 6 ; 10 \text { YR } 6 / 8\end{array}$ & Ma coesa & - & $\mathrm{Fr} \mathrm{c} / \mathrm{MFi}$ & LgPl LgPe & gp \\
\hline $2 \mathrm{Cxf} 3$ & $102-130+$ & $\begin{array}{l}10 \mathrm{YR} 7 / 1 \mathrm{~ms} \text {. a gr di } \\
2,5 \mathrm{YR} 4 / 6\end{array}$ & Ma coesa & - & Fr c/ MFi & $\mathrm{LgPl} \operatorname{LgPe}$ & - \\
\hline
\end{tabular}




\section{Quadro 1. Continuação}

\begin{tabular}{|c|c|c|c|c|c|c|c|}
\hline \multirow{2}{*}{ Horizonte } & \multirow{2}{*}{ Profundidade } & \multirow{2}{*}{ Cor (úmido) } & \multirow{2}{*}{ Estrutura } & \multicolumn{3}{|c|}{ Consistência } & \multirow[b]{2}{*}{ Trans. } \\
\hline & & & & Seca & Úmida & Molhada & \\
\hline \multicolumn{8}{|c|}{$\mathrm{cm}$} \\
\hline \multicolumn{8}{|c|}{$\begin{array}{c}\text { Toposseqüência } 2 \\
\text { Argissolo Amarelo eutrófico latossólico }\left(\mathrm{PA}_{4}\right)\end{array}$} \\
\hline Ap & $0-16$ & $10 \mathrm{YR} 3 / 3$ & $2 \mathrm{PMBls} 3 \mathrm{MGr}$ & $\mathrm{LD}$ & Fr & $\mathrm{Pl} \mathrm{Pe}$ & ср \\
\hline $\mathrm{BA}$ & $16-28$ & $7,5 \mathrm{YR} 4 / 6$ & $2 \mathrm{P} \mathrm{M} \mathrm{Bls}$ & - & $\mathrm{Fi}$ & $\mathrm{Pl} \mathrm{Pe}$ & gp \\
\hline Bt1 & $28-54$ & 7,5 YR 5/6 & $2 \mathrm{P} \mathrm{M} \mathrm{Bls}$ & - & $\mathrm{Fi}$ & $\mathrm{Pl} \mathrm{Pe}$ & $d p$ \\
\hline Bt2 & $54-85$ & 7,5 YR $5 / 8$ & $2 \mathrm{P} \mathrm{M} \mathrm{Bls}$ & . & $\mathrm{Fr}$ & $\mathrm{Pl} \mathrm{Pe}$ & $d p$ \\
\hline Bt3 & $85-126$ & 7,5 YR $5 / 8$ & $12 \mathrm{P} \mathrm{M} \mathrm{Bls}$ & - & Fr & $\mathrm{Pl} \mathrm{Pe}$ & $d p$ \\
\hline Bt4 & $126-160+$ & 7,5 YR $5 / 8$ & $1 \mathrm{P} \mathrm{M} \mathrm{Bls}$ & - & MFr & $\mathrm{Pl} \mathrm{Pe}$ & - \\
\hline \multicolumn{8}{|c|}{ Argissolo Vermelho eutrófico latossólico $\left(\mathrm{PV}_{2}\right)$} \\
\hline Ap & $0-12$ & 5 YR $4 / 4$ & $23 \mathrm{P} \mathrm{M} \mathrm{Bls}$ & $\mathrm{MD}$ & $\mathrm{Fi}$ & $\mathrm{Pl} \mathrm{Pe}$ & ср \\
\hline $\mathrm{BA}$ & $12-36$ & $2,5 Y R \quad 4 / 7$ & $2 \mathrm{P} \mathrm{M} \mathrm{Bls}$ & $\mathrm{D}$ & $\mathrm{Fi}$ & $\mathrm{Pl} \mathrm{Pe}$ & gp \\
\hline Bt1 & $36-66$ & $2,5 \mathrm{YR} 4 / 8$ & $12 \mathrm{P} \mathrm{M} \mathrm{Bls}$ & $\mathrm{Ma}$ & $\mathrm{Fr}$ & $\mathrm{Pl} \mathrm{Pe}$ & $\mathrm{dp}$ \\
\hline Bt2 & 66-114 & $2,5 Y R 4 / 8$ & $1 \mathrm{P} \mathrm{M} \mathrm{Bls}$ & $\mathrm{Ma}$ & $\mathrm{Fr}$ & $\mathrm{Pl} \mathrm{Pe}$ & $\mathrm{dp}$ \\
\hline Bt3 & $114-170+$ & $2,5 \mathrm{YR} 4 / 8$ & $1 \mathrm{P} \mathrm{M} \mathrm{Bls}$ & $\mathrm{Ma}$ & MFr & $\mathrm{Pl} \mathrm{Pe}$ & - \\
\hline \multicolumn{8}{|c|}{ Argissolo Acinzentado distrófico (PAC) } \\
\hline Ap 1 & $0-5$ & 10YR $3,5 / 1$ & Gs 2 P G Gr & - & Fr & $\mathrm{LgPl} \operatorname{LgPe}$ & gp \\
\hline Ap2 & $5-19$ & 10YR $4 / 1$ & $2 \mathrm{P} \mathrm{M} \mathrm{Bls}$ & - & $\mathrm{Fr}$ & $\mathrm{LgPl} \mathrm{LgPe}$ & cp \\
\hline $\mathrm{BA}$ & $19-40$ & 10YR 5/2 & $2 \mathrm{P} \mathrm{M} \mathrm{Bls}$ & - & $\mathrm{Fi}$ & $\mathrm{Pl} \mathrm{Pe}$ & gp \\
\hline Bt1 & $40-75$ & $10 \mathrm{YR} 6 / 2$ & $12 \mathrm{P} \mathrm{M} \mathrm{Bls}$ & - & $\mathrm{Fi}$ & MPl MPe & gp \\
\hline Bt2 & $75-126$ & 10YR 7/2 & $12 \mathrm{P} \mathrm{M} \mathrm{Bls}$ & - & $\mathrm{Fi}$ & MPl MPe & gp \\
\hline Bt3 & $126-150+$ & 10YR $7 / 2$ & $12 \mathrm{P} \mathrm{M} \mathrm{Bls}$ & - & $\mathrm{Fi}$ & MPl MPe & - \\
\hline \multicolumn{8}{|c|}{$\begin{array}{c}\text { Toposseqüência } 3 \\
\text { Espodossolo Ferrocárbico órtico argilúvico }\left(\mathrm{ES}_{1}\right)\end{array}$} \\
\hline Ap & $0-14$ & 10YR $3 / 1$ & Gs & So & So & $\tilde{n} \mathrm{Pl} \tilde{n} \mathrm{Pe}$ & $\mathrm{cp}$ \\
\hline $\mathrm{AE}$ & $14-34$ & 10YR 4/2 & Gs & So & So & $\tilde{\mathrm{n} P l} \tilde{\mathrm{n} P e}$ & gp \\
\hline E2 & $34-51$ & $10 Y R 5 / 3$ & Gs & So & So & $\tilde{n} \mathrm{Pl} \tilde{\mathrm{n} P e}$ & ap \\
\hline $\mathrm{Bh}$ & $51-58$ & 10 YR $3,5 / 3$ & $1 \mathrm{M} \mathrm{Bls}$ & . & $\mathrm{Fr}$ & $\mathrm{LgPl} \mathrm{LgPe}$ & $\mathrm{cp}$ \\
\hline Bhs & $58-76$ & $\begin{array}{l}\text { 10YR } 4 / 4 \\
\text { ms. c md di } 10 \text { YR } 4 / 6\end{array}$ & $2 \mathrm{P} \mathrm{M} \mathrm{Bls}$ & - & $\mathrm{Fi}$ & $\mathrm{LgPl} \mathrm{LgPe}$ & gp \\
\hline Bs & $75-92$ & $10 \mathrm{YR} 4 / 4$ & $1 \mathrm{M} \mathrm{Bls}$ & - & $\mathrm{Fi}$ & $\mathrm{LgPl} \mathrm{LgPe}$ & сp \\
\hline $2 \mathrm{Bt} 1$ & $92-112$ & $\begin{array}{l}\text { 10YR } 6 / 4 \\
\text { ms.c md df10YR 5/3 }\end{array}$ & $2 \mathrm{M} \mathrm{Bls}$ & - & Fi MFi & $\mathrm{Pl} \mathrm{Pe}$ & gp \\
\hline $2 \mathrm{Bt} 2$ & $112-160+$ & $\begin{array}{l}\text { 10YR } 6 / 6 \mathrm{~ms} . \mathrm{p} \text { pq di } \\
10 \mathrm{YR} 6 / 8\end{array}$ & $2 \mathrm{P} \mathrm{M} \mathrm{Bls}$ & - & $\mathrm{Fi}$ & $\mathrm{Pl} \mathrm{Pe}$ & - \\
\hline \multicolumn{8}{|c|}{ Espodossolo Ferrocárbico órtico $\left(\mathrm{ES}_{2}\right)$} \\
\hline Ap & $0-20$ & 10YR $3 / 1$ & Gs & So & So & $\tilde{n} \mathrm{Pl} \tilde{n} \mathrm{Pe}$ & ср \\
\hline $\mathrm{E}$ & $20-52$ & 10YR 5/2 & Gs & So & So & $\tilde{n} \mathrm{Pl} \tilde{n} \mathrm{Pe}$ & ao \\
\hline $\mathrm{Bh}$ & $52-57$ & $5 Y R 3 / 2$ & $1 \mathrm{P} \mathrm{Bls}$ & $\mathrm{LD}$ & $\mathrm{Fr}$ & $\mathrm{LgPl} \mathrm{LgPe}$ & go \\
\hline Bhs1 & $57-74$ & $5 Y R 3 / 2$ & $1 \mathrm{P} \mathrm{Bls}$ & $\mathrm{D}$ & $\mathrm{Fi}$ & $\tilde{n} \mathrm{Pl} \tilde{\mathrm{n} P e}$ & gp \\
\hline Bhs2 & $74-90$ & 5 YR $3 / 3$ & $1 \mathrm{P} \mathrm{Bls}$ & $\mathrm{D}$ & $\mathrm{Fi}$ & $\tilde{\mathrm{nPl}} \tilde{\mathrm{nPe}}$ & go \\
\hline 2 Chxf1 & $90-118$ & $\begin{array}{l}\text { Vr. } 7,5 \text { YR } 6 / 8 ; 10 \text { YR } 6 / 2 ; \\
10 \text { YR } 3 / 6 ; 2,5 \text { YR } 4 / 6\end{array}$ & Ma Mt coesa & ED & MFi & - & gp \\
\hline $2 \mathrm{Cxf} 2$ & $118-160+$ & $\begin{array}{l}\text { Vr. } 2,5 \text { YR } 6 / 6 ; 10 \text { YR } 5 / 6 \text {; } \\
\text { 10YR } 3 / 3\end{array}$ & Ma Mt coesa & ED & Mfi & - & - \\
\hline \multicolumn{8}{|c|}{$\begin{array}{c}\text { Mucurici } \\
\text { Argissolo Amarelo distrófico }\left(\mathrm{PA}_{5}\right)\end{array}$} \\
\hline Ap1 & $0-7$ & $10 Y R 3 / 1$ & Gs $2 \mathrm{G} \mathrm{Gr}$ & - & - & $\tilde{n} P l \tilde{n} P e$ & gp \\
\hline Ap2 & $7-17$ & 10YR $3 / 2$ & $12 \mathrm{P} \mathrm{Bls}$ & - & - & $\tilde{n} \mathrm{Pl} \mathrm{LgPe}$ & $\mathrm{cp}$ \\
\hline $\mathrm{AB}$ & $17-35$ & $10 \mathrm{YR} 3 / 3$ & $12 \mathrm{P} \mathrm{Bls}$ & - & - & $\tilde{\mathrm{nPl}} \mathrm{LgPe}$ & $\mathrm{cp}$ \\
\hline $\mathrm{BA}$ & $35-48$ & $2,5 \mathrm{YR} 5 / 4$ & $12 \mathrm{P} \mathrm{M} \mathrm{Bls}$ & - & - & LgPl LgPe & gp \\
\hline Bt1 & $48-65$ & $10 \mathrm{YR} 5 / 8$ & $1 \mathrm{P} \mathrm{M} \mathrm{Bls}$ & - & - & $\mathrm{Pl} \mathrm{Pe}$ & $d p$ \\
\hline Bt2 & $65-128$ & 10 YR $5 / 8$ & $1 \mathrm{P} \mathrm{M} \mathrm{Bls}$ & - & . & $\mathrm{Pl} \mathrm{Pe}$ & $d p$ \\
\hline Bt3 & $128-150+$ & 10 YR $5 / 8$ & $1 \mathrm{P} \mathrm{M} \mathrm{Bls}$ & - & . & $\mathrm{Pl} \mathrm{Pe}$ & - \\
\hline
\end{tabular}

Estrutura: 1 - fraca; 2 - moderada; 3 - forte; MP: muito pequena; P: pequena; M: média; G: grande; Gr: granular; Bla: blocos angulares; Bls: blocos subangulares; Gs: grão simples. Ma: maciça. Consistência: So: solto; Ma: macio; LD: ligeiramente dura; D: dura; MD: muito dura; ED: extremamente dura; MFr: muito friável; Fr: friável; Fi - firme; MFi: muito firme; ñ: não; Lg: ligeiramente; Mt: muito; Pl: plástico; Pe: pegajoso. Transição: p: plana; o: ondulada; a: abrupta; g: gradual; d: difusa; c: clara. Cor: vr: variegado; ms: mosqueado; p: pouco; c: comum; a: abundante; di: distinto; df: difuso; pq: pequeno; md: médio; gr: grande. 
avermelhadas (matiz 2,5YR) e estrutura dominantemente em blocos subangulares no horizonte $\mathrm{Bt}$, com fraco a moderado grau de desenvolvimento (aspecto maciço). Sob pressão, os blocos da parte superior do Bt rompiam-se na forma de "lascas" finas mais ou menos paralelos à parede do perfil, o que parece uma característica peculiar de Argissolos e Latossolos desenvolvidos de sedimentos mais finos do Grupo Barreiras.

As avaliações da estrutura e consistência, aliadas ao exame em campo de resistência à penetração da faca, possibilitam a identificação do caráter latossólico e coeso (Embrapa, 1999) em alguns perfis de Argissolos. O caráter latossólico foi verificado nos perfis de maiores cotas das toposseqüências 1 e 2, tanto para Argissolos Amarelos como para Argissolos Vermelhos, caracterizando intensa transformação pedogenética de seus materiais. O caráter coeso foi observado em todos os Argissolos, mostrando-se, contudo, mais típico nos perfis $\mathrm{PA}_{1}$ (toposseqüência 1), $\mathrm{PA}_{4}, \mathrm{PV}_{2}, \mathrm{PAC}$ (toposseqüência 2) e $\mathrm{PA}_{5}$ (perfil de Mucurici), nos horizontes BA e, ou, Bt1. A adoção desse caráter para solos vermelhos não é contemplada pelo atual Sistema Brasileiro de Classificação de Solos (SiBCS) (Embrapa, 1999), sendo utilizado como critério de distinção, somente, na classe dos Latossolos Amarelos. Para melhor visualização, os horizontes coesos estão em negrito nos quadros subseqüentes.

Foram coletados, ainda, dois perfis de Espodossolos que compõem a terceira toposseqüência. Localizado em cota mais alta, o perfil $\mathrm{ES}_{1}$ apresentou característica transicional com Argissolo Amarelo. Neste, não foi observado fragipã, porém foi identificado horizonte $\mathrm{Bt}$ abaixo de horizonte espódico, conferindo-lhe o atributo argilúvico em sua classificação (Embrapa, 1999).

\section{Caracterização química}

Os resultados das análises químicas (Quadro 2) revelam que os solos vermelhos e amarelos, localizados em posição de topo e encosta superior de relevo suaveondulado nas toposseqüências 1 e 2 (Quadro 2), apresentaram saturação por bases (V \%) maior que $50 \%$, caracterizando solos eutróficos. Esse fato pode ser decorrente do enriquecimento de cátions trocáveis devido ao intemperismo de minerais (plagioclásios) de rochas mesocráticas do Complexo Paraíba do Sul (biotita e, ou, hornblenda-granada gnaisses do PréCambriano) (Silva et al., 1987), uma vez que os valores $\mathrm{V} \%$ mostraram-se maiores com o aumento da profundidade, com exceção do $\mathrm{PA}_{1}$. Ou seja, trata-se de solos desenvolvidos de rochas do cristalino que se encontram mais à superfície, às vezes aflorando-se, em ambiente tipico dos sedimentos do Barreiras. Neste caso, o manto de intemperismo não é tão profundo, e a ciclagem de nutrientes e a sazonalidade climática explicam a eutrofia. Os demais perfis são distróficos ou epieutróficos, sendo este último aspecto devido ao enriquecimento via aplicações de corretivos, uma vez que a área se apresenta cultivada com eucalipto.
De modo geral, a capacidade de troca de cátions (CTC) foi maior nos horizontes superficiais (Quadro 2). Para os horizontes Bt dos Argissolos, seus valores foram baixos, sempre inferiores a $5 \mathrm{cmol}_{\mathrm{c}} \mathrm{kg}^{-1}$, refletindo a mineralogia caulinítica desses materiais. Valores semelhantes foram encontrados por Oliveira et al. (1968), Silva \& Ribeiro (1998), Moreau (2001), e outros, para Latossolos e Argissolos brasileiros.

Por se tratar de solos com argila de atividade baixa, a CTC mostrou-se dependente do teor de C orgânico do solo, apresentando correlação positiva com seus valores $\left(r=0,60^{*}\right)$. Essa baixa correlação pode ser devido à diversidade na fração orgânica dos horizontes superficiais e subsuperficiais, condicionada pelo manejo e processo pedogenético entre os Argissolos e Espodossolos. Melhores ajustes foram obtidos ao se analisarem os resultados por perfil.

\section{Características físicas}

A partir dos resultados de análises físicas (Quadro 2), foram identificados solos com textura muito argilosa (Argissolos localizados nas cotas mais altas das toposseqüências 1 e 2), solos com textura argilosa (demais Argissolos) e solos arenosos (Espodossolos). Observou-se tendência de aumento no conteúdo de argila em profundidade e diminuição no percentual de areias grossa e fina. A translocação de argila pode ser evidenciada pelos gradientes texturais de até 4 para o Argissolo e 17 para o Espodossolo. De acordo com UFV (1984), a ocorrência de gradientes acentuados nos Tabuleiros Costeiros deve-se à remoção preferencial das partículas finas, conferida pela estabilidade natural da paisagem. Contudo, o processo de destruição de argila (partículas de caulinitas de pequeno tamanho e, ou, alta desordem estrutural) pode ocorrer conjuntamente a essa argiluviação, aumentando, ainda mais, a diferenciação textural.

No $\mathrm{PA}_{3}$, foi determinado teor de argila de 52 dag kg-1 (Quadro 2) para o fragipã, muito superior aos 35 dag kg-1, sugerido por Petersen et al. (1970) e Richie et al. (1974) como limite máximo para formação destes horizontes. Possivelmente, sua mineralogia caulinítica, aliada à alta relação argila fina/argila grossa (AGF/AGG) (Quadro 2), contribui para ocorrência de fragipã de textura argilosa. Já para os Espodossolos $\left(\mathrm{ES}_{2}\right)$, o teor médio de argila do fragipã foi de $33 \mathrm{dag} \mathrm{kg}^{-1}$.

Além dos fragipãs, os Espodossolos $\left(\mathrm{ES}_{1}\right.$ e $\left.\mathrm{ES}_{2}\right)$ também apresentaram horizontes Bh e Bhs de textura arenosa, com nítido endurecimento (Quadro 1). Esses resultados indicam a possibilidade de cimentação destes horizontes arenosos por géis amorfos e por materiais de baixa cristalinidade de $\mathrm{Si}, \mathrm{Al}$ e, ou, Fe, com presença de C, como descrito por Tazaki et al. (1989) e corroborado por Andrade et al. (2003). Aliada à cimentação química, há a possibilidade de existência de "pontes" de materiais muito finos ligando as partículas do solo, uma vez que os horizontes espódicos estudados apresentaram, em média, 13 dag $\mathrm{kg}^{-1} \mathrm{de}$ 
Quadro 2. Caracterização física e química dos solos estudados

\begin{tabular}{|c|c|c|c|c|c|c|c|c|c|c|c|c|c|c|c|c|c|c|c|c|c|}
\hline & Arei & & & & & rgila & & $\mathbf{A D}^{(1)}$ & & $\mathrm{AGF}^{(3)}$ & & & & & SE & pl & $\mathbf{H}$ & & & & \\
\hline 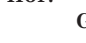 & Grossa & Fina & anc & Argña & $0,2-2 \mathrm{~m}$ & $<0,2 \mathrm{~m}$ & $\Sigma$ & Água & $\mathbf{G F}^{(2)}$ & AGG & DS & Do & 01. & $\mathrm{H}_{2} \mathrm{O}$ & BET-N 2 & $\mathrm{H}_{2} \mathrm{O}$ & $\mathrm{KCl}$ & $\mathrm{s}$ & C10 & 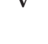 & MO \\
\hline & & & $x_{1}$ & —dag & $\mathrm{kg}^{-1}$ & & & & $\%$ & & $-\mathrm{g} \mathrm{cm}$ & $n^{-3}-$ & $\%$ & & $n^{2} g^{-1}-$ & & & $-\mathrm{cmol}$ & $\mathrm{l}_{\mathrm{c}} \mathrm{kg}^{-1}-$ & $\%$ & dag $\mathrm{kg}^{-1}$ \\
\hline & & & & & & & & & & rfil - PI & & & & & & & & & & & \\
\hline A & 38 & 8 & 5 & 49 & 8 & 32 & 40 & 29 & 41 & 4,05 & 1,28 & 2,27 & 44 & 75 & 35 & 5,7 & 5,5 & 6,70 & 8,40 & 80 & 4,7 \\
\hline BA & 32 & 8 & 4 & 56 & 7 & 37 & 44 & 40 & 29 & 4,99 & 1,45 & 2,06 & 30 & 42 & 40 & 5,9 & 5,5 & 2,59 & 3,50 & 74 & 2,1 \\
\hline Bt1 & 22 & 6 & 5 & 67 & 15 & 35 & 50 & 35 & 48 & 2,27 & 1,43 & 2,27 & 37 & 22 & 37 & 6,1 & 5,5 & 1,70 & 2,20 & 77 & 1,4 \\
\hline Bt2 & 25 & 7 & 3 & 65 & 12 & 37 & 49 & 0 & 100 & 3,08 & 1,35 & 2,50 & 46 & 34 & 36 & 6,2 & 5,6 & 1,35 & 1,45 & 93 & 0,8 \\
\hline Bt3 & 22 & 7 & 6 & 65 & nd & nd & nd & 0 & 100 & nd & 1,27 & 2,44 & 48 & 34 & nd & 6,3 & 5,7 & 1,29 & 1,39 & 93 & 0,6 \\
\hline & & & & & & & & & & rfil - P & & & & & & & & & & & \\
\hline A & 70 & 11 & 3 & 16 & 6 & 7 & 13 & 7 & 56 & 1,19 & 1,29 & 2,44 & 47 & 166 & 38 & 6,1 & 5,8 & 5,70 & 7,60 & 75 & 4,7 \\
\hline $\mathrm{AB}$ & 66 & 14 & 3 & 17 & 7 & 10 & 17 & 16 & 6 & 1,58 & 1,60 & 2,60 & 38 & 74 & 41 & 6,5 & 5,7 & 2,09 & 2,49 & 84 & 1,4 \\
\hline BA & 46 & 13 & 4 & 37 & 13 & 23 & 36 & 34 & 8 & 1,69 & 1,62 & 2,27 & 29 & 51 & 45 & 6,7 & 5,8 & 2,06 & 2,56 & 80 & 1,5 \\
\hline Bt1 & 24 & 7 & 1 & 68 & 18 & 32 & 50 & 50 & 26 & 1,75 & 1,54 & 1,96 & 21 & 37 & 41 & 6,9 & 5,5 & 1,65 & 3,15 & 52 & 1,3 \\
\hline Bt2 & 24 & 7 & 0 & 69 & 12 & 38 & 50 & 34 & 51 & 3,17 & 1,49 & 2,33 & 36 & 36 & 42 & 5,4 & 4,9 & 0,99 & 3,59 & 28 & 1,0 \\
\hline Bt3 & 24 & 8 & 1 & 67 & 2 & 37 & 39 & 1 & 99 & 21,13 & 1,46 & 2,30 & 36 & 32 & 39 & 4,7 & 4,6 & 0,37 & 2,87 & 13 & 0,6 \\
\hline & & & & & & & & & & rfil - P & & & & & & & & & & & \\
\hline Ap1 & 78 & 10 & 1 & 11 & 3 & 5 & 8 & 8 & 27 & 1,34 & 1,44 & 2,47 & 42 & 96 & 36 & 5,3 & 4,7 & 1,36 & 4,56 & 30 & 2,1 \\
\hline Ap2 & 80 & 8 & 0 & 12 & 4 & 6 & 10 & 9 & 25 & 1,80 & 1,52 & 2,27 & 33 & 79 & 37 & 5,5 & 4,9 & 1,53 & 3,74 & 41 & 1,8 \\
\hline $\mathrm{BA}$ & 67 & 12 & 1 & 20 & 3 & 16 & 19 & 18 & 10 & 4,79 & 1,54 & 2,50 & 38 & 47 & 43 & 5,7 & 5,0 & 1,65 & 2,75 & 60 & 1,2 \\
\hline Bt1 & 45 & 12 & 1 & 42 & 3 & 27 & 30 & 32 & 24 & 7,92 & 1,45 & 2,33 & 38 & 39 & 39 & 5,9 & 5,0 & 1,09 & 1,99 & 55 & 1,1 \\
\hline Bt2 & 34 & 11 & 0 & 55 & 2 & 37 & 39 & 39 & 29 & 21,13 & 1,56 & 2,44 & 36 & 40 & 40 & 5,2 & 4,5 & 0,66 & 2,66 & 25 & 0,8 \\
\hline Bt3 & 35 & 9 & 1 & 55 & 1 & 37 & 38 & 0 & 100 & 35,31 & 1,50 & 2,20 & 32 & 35 & 38 & 4,8 & 4,5 & 0,16 & 2,47 & 7 & 0,9 \\
\hline & & & & & & & & & & rfil - P & & & & & & & & & & & \\
\hline Ap & 80 & 10 & 0 & 10 & 3 & 4 & 7 & 6 & 40 & 1,44 & 1,46 & 2,33 & 37 & 133 & nd & 5,6 & 4,8 & 1,08 & 3,19 & 34 & 1,8 \\
\hline $\mathrm{AB}$ & 77 & 11 & 3 & 9 & 3 & 7 & 10 & 8 & 11 & 2,31 & 1,52 & 2,50 & 39 & 145 & nd & 5,7 & 4,8 & 0,87 & 2,57 & 34 & 1,4 \\
\hline BA & 68 & 13 & 5 & 14 & 3 & 13 & 16 & 13 & 7 & 4,35 & 1,56 & 2,44 & 36 & 101 & nd & 5,8 & 4,8 & 0,80 & 2,11 & 38 & 1,3 \\
\hline Bt1 & 50 & 17 & 8 & 25 & 2 & 19 & 21 & 24 & 4 & 8,06 & 1,54 & 2,35 & 35 & 67 & nd & 5,9 & 4,8 & 0,76 & 1,87 & 41 & 1,0 \\
\hline $\mathrm{Cx} 1$ & 44 & 14 & 11 & 31 & 3 & 28 & 31 & 15 & 52 & 10,08 & 1,63 & 2,33 & 30 & 461 & nd & 5,9 & 4,9 & 0,50 & 4,90 & 10 & 1,4 \\
\hline Cxf2 & 43 & 12 & 9 & 36 & 3 & 34 & 37 & 27 & 25 & 10,06 & 1,53 & 2,13 & 28 & 184 & nd & 5,5 & 4,7 & 0,55 & 4,74 & 11 & 1,2 \\
\hline $2 \mathrm{Cxf} 3$ & 30 & 8 & 10 & 52 & 6 & 44 & 50 & 35 & 33 & 6,82 & nd & 2,13 & nd & 52 & nd & 5,2 & 4,5 & 0,51 & 3,31 & 15 & 0,6 \\
\hline & & & & & & & & & & rfil - P & & & & & & & & & & & \\
\hline Ap & 53 & 11 & 2 & 34 & 6 & 17 & 23 & 19 & 44 & 2,82 & 1,46 & 2,30 & 36 & 76 & nd & 6,4 & 4,6 & 4,21 & 7,11 & 59 & 2,6 \\
\hline $\mathrm{BA}$ & 37 & 11 & 4 & 48 & 4 & 33 & 37 & 34 & 29 & 7,58 & 1,51 & 2,33 & 35 & 41 & nd & 6,1 & 4,8 & 2,84 & 4,24 & 67 & 1,6 \\
\hline Bt1 & 25 & 8 & 5 & 62 & 5 & 43 & 48 & 45 & 27 & 8,00 & 1,43 & 2,30 & 38 & 40 & nd & 6,1 & 4,8 & 2,61 & 3,91 & 67 & 1,1 \\
\hline Bt2 & 21 & 7 & 4 & 68 & 10 & 41 & 51 & 43 & 37 & 3,96 & 1,40 & 2,20 & 36 & 40 & nd & 6,1 & 5,1 & 2,32 & 3,31 & 70 & 0,6 \\
\hline Bt3 & 17 & 6 & 4 & 73 & 40 & 15 & 55 & 0 & 100 & 0,38 & 1,31 & 2,38 & 45 & 31 & nd & 6,1 & 5,3 & 1,99 & 2,49 & 80 & 0,5 \\
\hline $\mathrm{Bt} 4$ & 15 & 6 & 6 & 73 & 54 & 2 & 56 & 0 & 100 & 0,05 & 1,25 & 2,47 & 49 & 39 & nd & 6,0 & 5,3 & 1,59 & 1,90 & 84 & 0,3 \\
\hline & & & & & & & & & & rfil - PI & & & & & & & & & & & \\
\hline Ap & 41 & 8 & 7 & 44 & 4 & 34 & 38 & 31 & 30 & 8,93 & 1,22 & 2,20 & 44 & 69 & nd & 5,9 & 5,0 & 1,30 & 3,49 & 37 & 2,4 \\
\hline BA & 25 & 6 & 7 & 62 & 4 & 46 & 50 & 40 & 35 & 11,30 & 1,49 & 2,25 & 34 & 51 & nd & 6,1 & 5,0 & 0,78 & 1,68 & 46 & 1,1 \\
\hline Bt1 & 31 & 7 & 7 & 55 & 11 & 41 & 52 & 0 & 100 & 3,78 & 1,39 & 2,41 & 42 & 77 & nd & 6,4 & 5,3 & 0,46 & 0,76 & 61 & 0,6 \\
\hline Bt2 & 32 & 9 & 8 & 51 & 12 & 34 & 46 & 0 & 100 & 2,74 & 1,34 & 2,41 & 44 & 83 & nd & 6,6 & 5,4 & 0,39 & 0,69 & 57 & 0,2 \\
\hline Bt3 & 25 & 7 & 10 & 58 & 47 & 7 & 54 & 0 & 100 & 0,15 & 1,42 & 2,50 & 43 & 80 & nd & 6,6 & 5,5 & 0,30 & 0,50 & 60 & 0,3 \\
\hline & & & & & & & & & & rfil PA & & & & & & & & & & & \\
\hline Ap1 & 68 & 12 & 4 & 16 & 3 & 8 & 11 & 9 & 44 & 2,41 & 1,52 & 2,47 & 38 & 115 & nd & 5,5 & 4,5 & 0,98 & 2,78 & 35 & 1,6 \\
\hline Ap2 & 60 & 13 & 11 & 16 & 4 & 15 & 19 & 15 & 6 & 4,12 & 1,58 & 2,44 & 35 & 91 & nd & 5,6 & 4,6 & 1,03 & 3,03 & 34 & 1,8 \\
\hline $\mathrm{BA}$ & 48 & 12 & 2 & 38 & 4 & 29 & 33 & 30 & 21 & 6,69 & 1,50 & 2,35 & 36 & 50 & nd & 5,9 & 4,6 & 0,78 & 2,08 & 38 & 1,1 \\
\hline Bt1 & 33 & 10 & 2 & 55 & 5 & 46 & 51 & 41 & 25 & 9,00 & 1,56 & 2,38 & 34 & 51 & nd & 6,2 & 4,8 & 0,75 & 1,45 & 52 & 0,9 \\
\hline Bt2 & 19 & 7 & 6 & 68 & 8 & 55 & 63 & 53 & 22 & 6,60 & 1,53 & 2,27 & 33 & 57 & nd & 6,4 & 4,9 & 0,97 & 1,87 & 52 & 0,7 \\
\hline Bt3 & 24 & 6 & 4 & 66 & 8 & 51 & 59 & 54 & 18 & 6,59 & 1,49 & 2,22 & 33 & 58 & nd & 6,6 & 5,0 & 1,06 & 1,56 & 68 & 0,5 \\
\hline & & & & & & & & & & rfil- ES & & & & & & & & & & & \\
\hline Ap & 81 & 12 & 5 & 2 & 1 & 0 & 1 & 1 & 50 & 0,00 & 1,53 & 2,63 & 42 & 370 & nd & 4,7 & 3,8 & 1,24 & 9,54 & 13 & 2,0 \\
\hline $\mathrm{AE}$ & 82 & 11 & 3 & 4 & nd & nd & nd & 1 & 75 & nd & 1,62 & 2,53 & 36 & nd & nd & 4,7 & 3,8 & 0,89 & 8,18 & 11 & 1,6 \\
\hline $\mathrm{E}$ & 75 & 16 & 7 & 2 & nd & nd & nd & 1 & 50 & nd & 1,64 & 2,60 & 37 & nd & nd & 4,8 & 3,9 & 0,77 & 5,76 & 13 & 1,6 \\
\hline $\mathrm{Bh}$ & 70 & 16 & 4 & 10 & nd & nd & nd & 6 & 40 & nd & 1,51 & 2,56 & 41 & 119 & nd & 4,8 & 3,9 & 0,57 & 4,88 & 12 & 1,0 \\
\hline Bhs & 65 & 14 & 6 & 15 & 1 & 11 & 12 & 11 & 27 & 7,80 & 1,48 & 2,44 & 39 & 158 & nd & 4,8 & 4,0 & 0,51 & 4,32 & 12 & 1,0 \\
\hline Bs & 67 & 14 & 2 & 17 & 1 & 11 & 12 & 10 & 41 & 9,14 & 1,47 & 2,53 & 42 & 144 & nd & 4,8 & 4,2 & 0,44 & 3,85 & 12 & 0,8 \\
\hline $2 \mathrm{Bt} 1$ & 53 & 11 & 2 & 34 & 2 & 29 & 31 & 22 & 35 & 12,62 & 1,43 & 2,47 & 42 & 67 & nd & 4,9 & 4,3 & 0,43 & 3,03 & 14 & 0,7 \\
\hline $2 \mathrm{Bt} 2$ & 52 & 8 & 4 & 36 & 3 & 37 & 40 & 27 & 25 & 12,57 & 1,55 & 2,41 & 36 & 50 & nd & 5,0 & 4,3 & 0,39 & 1,70 & 23 & 0,6 \\
\hline & & & & & & & & & & rfil - ES & & & & & & & & & & & \\
\hline Ap & 83 & 10 & 4 & 3 & nd & nd & nd & 1 & 67 & nd & nd & 2,50 & nd & 179 & nd & 4,4 & 3,4 & 0,54 & 10,94 & 5 & 2,3 \\
\hline $\mathrm{E}$ & 80 & 13 & 6 & 1 & nd & nd & nd & 1 & 0 & nd & nd & 2,50 & nd & nd & nd & 4,5 & 3,6 & 0,48 & 9,88 & 5 & 1,6 \\
\hline $\mathrm{Bh}$ & 75 & 8 & 6 & 11 & nd & nd & nd & 9 & 18 & nd & nd & 2,50 & nd & 127 & nd & 4,5 & 4,0 & 0,44 & 9,14 & 5 & 1,6 \\
\hline Bhs1 & 67 & 11 & 4 & 18 & 0 & 9 & 9 & 7 & 61 & - & 1,45 & 2,44 & 41 & 208 & nd & 4,6 & 4,1 & 0,42 & 5,31 & 8 & 1,3 \\
\hline Bhs2 & 74 & 11 & 4 & 11 & nd & nd & nd & 4 & 64 & nd & 1,10 & 2,47 & 55 & 410 & nd & 4,8 & 4,1 & 0,39 & 4,80 & 8 & 1,2 \\
\hline $2 \mathrm{Chxf} 1$ & 54 & 10 & 7 & 29 & 1 & 12 & 14 & 0 & 100 & 10,26 & 1,38 & 2,08 & 34 & 538 & nd & 4,8 & 4,3 & 0,36 & 4,57 & 8 & 1,1 \\
\hline $2 \mathrm{Cxf} 2$ & 46 & 8 & 9 & 37 & 3 & 28 & 31 & 0 & 100 & 10,96 & 1,69 & 2,41 & 30 & 117 & nd & 5,1 & 4,2 & 0,25 & 1,26 & 20 & 0,6 \\
\hline & & & & & & & & & & rfil - PA & & & & & & & & & & & \\
\hline Ap1 & 64 & 12 & 5 & 19 & 3 & 9 & 12 & 14 & 26 & 3,03 & nd & 2,25 & nd & 61 & 40 & 5,0 & 4,0 & 0,90 & 6,20 & 15 & 2,2 \\
\hline Ap2 & 62 & 11 & 4 & 23 & 3 & 12 & 16 & 19 & 17 & 3,66 & nd & 2,33 & nd & 50 & 40 & 7,0 & 3,9 & 0,20 & 6,80 & 3 & 1,0 \\
\hline $\mathrm{AB}$ & 57 & 13 & 3 & 27 & 2 & 13 & 15 & 21 & 22 & 6,63 & nd & 2,33 & nd & 54 & 40 & 4,6 & 4,0 & 0,07 & 6,67 & 1 & 1,0 \\
\hline BA & 54 & 13 & 3 & 30 & nd & nd & nd & 26 & 13 & nd & nd & 2,30 & nd & nd & nd & 4,6 & 4,0 & 0,19 & 5,49 & 4 & 1,0 \\
\hline Bt1 & 49 & 11 & 4 & 36 & 4 & 21 & 26 & 29 & 19 & 5,16 & nd & 2,33 & nd & 35 & 43 & 4,6 & 4,0 & 0,08 & 4,68 & 2 & 1,6 \\
\hline Bt2 & 44 & 10 & 3 & 43 & 3 & 26 & 29 & 34 & 21 & 9,69 & nd & 2,38 & nd & 32 & 40 & 4,6 & 4,0 & 0,02 & 3,62 & 1 & 1,4 \\
\hline Bt3 & 41 & 10 & 5 & 44 & 2 & 30 & 32 & 1 & 98 & 18,12 & nd & 2,33 & nd & 31 & 40 & 4,9 & 4,2 & 0,05 & 3,35 & 2 & 0,0 \\
\hline
\end{tabular}

(1) Argila dispersa. ${ }^{(2)}$ Grau de floculação. ${ }^{(3)}$ Argila fina/argila grossa. ${ }^{(4)}$ Porosidade. nd: não determinado. 
argila, constituída basicamente (90 a $100 \%$ ) de partículas menores que 0,2 $\mu \mathrm{m}$ (Quadro 2).

A fração argila fina (AGF) mostrou-se dominante em todos os solos estudados, com valores médios de 93 e 79 \% da argila total (Quadro 2) para os Espodossolos e Argissolos, respectivamente. O aumento da relação AGF/AGG (Quadro 2) com a profundidade caracteriza a presença de processo de argiluviação. Seus maiores valores foram obtidos nos horizontes BA e, ou, Bt1 (entre 4 e 11) na maioria dos Argissolos estudados, estando relacionado com a forte resistência à penetração com a faca e demais características morfológicas, que sugeriram a adoção do caráter "coeso" para esses solos. Nos Argissolos cujo gradiente textural se mostrou mais elevado, as relações AGF/ AGG apresentaram-se altas também nos horizontes Bt2 e Bt3 (Quadro 2). De acordo com Jacomine (1996) e Moreau (2001), os Argissolos Amarelos com mudança textural mais pronunciada apresentam o caráter coeso até maiores profundidades. Contudo, nesses perfis, as maiores coesões ainda foram observadas nos horizontes BA e, ou, Bt1.

A relação positiva entre os teores de argila fina (caulinitas menores de 0,2 $\mu \mathrm{m}$ ) e argila dispersa em água (AD) (Figura 2) contribui para compreensão sobre a formação dos horizontes coesos. Essa relação sugere maior probabilidade de translocação das partículas mais finas, entre ou dentro do mesmo horizonte, aumentando a superfície de contato entre os constituintes do solo (agregados e partículas) e promovendo expressivo ganho de resistência (Lamotte et al., 1997a,b). Para parte dos perfis estudados, os horizontes de maior resistência à penetração da faca e martelo pedológico coincidem com aqueles com maior relação AGF/AGG.

De acordo com Lamotte et al. (1997a), um pequeno aumento no teor de argila muito fina pode promover a

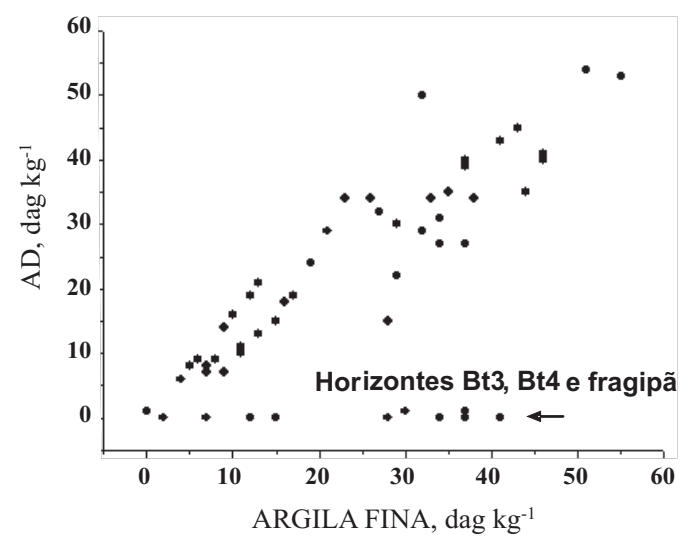

Figura 2. Relação entre argila dispersa em água (AD) e argila fina do material desferrificado, considerando todos os horizontes dos solos estudados. Obtenção de coeficiente $r=0,81 *$ (correlação de Pearson) ao desconsiderar os horizontes Bt3, Bt4 e fragipã (grupo de pontos indicado pela seta na figura). ocorrência de horizontes endurecidos ("hardsetting") em solos. Esses autores, estudando um Neossolo Quartzarênico do norte de Camarões-África, observaram que a única diferença entre horizontes não-endurecidos e endurecidos foi acréscimo de apenas 1,3 dag $\mathrm{kg}^{-1}$ de solo no conteúdo de argila fina $(<0,2 \mu \mathrm{m})$ nestes últimos. Assim, uma pequena quantidade de partículas finas dispersas poderia migrar e depositar-se nos poros, presentes entre os constituintes do solo, formando pontes de ligação que, conseqüentemente, aumentariam a coesão. A longo prazo, essas partículas poderiam obstruir parte da porosidade, podendo apresentar-se como cútans de iluviação. Essa pouca necessidade de argila fina para promover a coesão poderia explicar a presença de horizontes coesos em Latossolos Amarelos dos Tabuleiros Costeiros. A presença de feição de iluviação foi também constatada por Melo \& Santos (1996) e Silva et al. (1998) para Argissolos Amarelos e Latossolos Amarelos coesos dos Tabuleiros Costeiros de Pernambuco e Alagoas, respectivamente.

Corroborando esses resultados, Shanmuganathan \& Oades (1983) e Barzegar et al. (1995) descreveram relação positiva entre argila dispersa em água e resistência à penetração. Segundo os autores, esta diminuiu com o aumento no teor de Fe.

As maiores relações AGF/AGG não foram observadas nos horizontes coesos dos perfis $\mathrm{PV}_{1}, \mathrm{PA}_{1}$, $\mathrm{PA}_{2}$ e $\mathrm{PA}_{5}$, e sim nos horizontes mais subsuperficiais (não-coesos). Contudo, os valores de superfície específica (SE) determinados por BET-N ${ }_{2}\left(\mathrm{SE}_{\mathrm{BET}}\right)$ para os referidos perfis apresentaram correlação significativa com a densidade do solo $\left(r=0,77^{0,1 \%}\right)$. Nos horizontes BA e Bt1, desses perfis, foram observados os maiores valores de $\mathrm{SE}_{\mathrm{BET}}$ e resistência à penetração de faca e ao martelo pedológico, sugerindo que a gênese dos coesos pode ser, também, decorrente da iluviação de partículas ainda bem menores que $0,2 \mu \mathrm{m}$.

Para todos os perfis, os valores médios de superfície específica, determinados por adsorção de vapor de água $\left(\mathrm{SE}_{\mathrm{H}_{2} \mathrm{O}}\right)$ na fração TFSA, foram de $120 \mathrm{~m}^{2} \mathrm{~g}^{-1}$ para o horizonte A, $46 \mathrm{~m}^{2} \mathrm{~g}^{-1}$, para o Bt, $194 \mathrm{~m}^{2} \mathrm{~g}^{-1}$ para o Bh e $270 \mathrm{~m}^{2} \mathrm{~g}^{-1}$ para Cx (Quadro 2). Esses resultados demonstram a importância dos compostos orgânicos, principalmente ácidos fúlvicos e húmicos (horizonte Bh e topo do Cx), no aumento dos valores de SE.

A densidade do solo variou de 1,10 a 1,69 $\mathrm{g} \mathrm{cm}^{-3}$, sendo os maiores valores observados nos fragipãs e horizontes coesos. Não é rara a descrição de horizontes coesos com valores de densidade do solo (Ds) superiores a 1,70 $\mathrm{g} \mathrm{cm}^{-3}$ (Oliveira \& Melo, 1970; Achá-Panoso, 1976), sendo, em alguns casos, mais elevada que os horizontes fragipãs dos Espodossolos e Argissolos dos Tabuleiros Costeiros. No presente estudo, a variação no teor de argila entre os horizontes coesos e os fragipãs comprometeu tal comparação. Contudo, os valores de Ds dos horizontes coesos deste estudo variaram de 1,45 a $1,60 \mathrm{~g} \mathrm{~cm}^{-3}$, próximo aos obtidos 
para os fragipãs dos perfis $\mathrm{PA}_{3}$ e $\mathrm{ES}_{2}$, de $1,50 \mathrm{e}$ $1,69 \mathrm{~g} \mathrm{~cm}^{-3}$, respectivamente (Quadro 2). Em razão de a densidade específica de materiais amorfos de $\mathrm{Si}$, $\mathrm{Al}$ e, ou, $\mathrm{Fe}$ ser inferior àquela de suas formas cristalinas, os altos valores de Ds dos horizontes coesos indicam inconsistência da hipótese de cimentação química (géis de silício, por exemplo) proposta por Meireles \& Ribeiro (1995), ou seja, considerando-se que o ganho de densidade de $22 \%$ (Ds de 1,4 para $1,7 \mathrm{~g} \mathrm{~cm}^{-3}$ ) do horizonte não-coeso para o coeso fosse decorrente, principalmente, da acumulação de materiais amorfos, seguramente, a consistência deste material seria mais típica de um fragipã ou mesmo de um duripã.

A gênese dos horizontes coesos por meio de iluviação de argilas foi proposta por Achá-Panoso (1976), sem menção do fracionamento da argila. Assim, até o presente momento, não se conhecia detalhadamente a distribuição granulométrica da fração mais fina. Nesse sentido, os resultados obtidos no presente trabalho resgatam a referida hipótese da gênese dos coesos, sugerindo que sua formação se deve à iluviação de argila muito fina e posterior entupimento da porosidade.

\section{Caracterização mineralógica da fração TFSA}

Os espectros de difratometria de raios X (DRX) (Figura 3) sugerem grande homogeneidade mineralógica dos solos estudados, revelando o quartzo na fração grosseira (areia e silte) e a caulinita na fração argila, como constituintes principais.

Na análise em lupa, observou-se que, nos Argissolos, as frações areia grossa, média e fina são compostas, quase exclusivamente, de quartzo. Em quantidade traço, foram observados minerais com atração magnética (magnetita) e concreções avermelhadas ou bicromadas (vermelho e amarelo), compostas por quartzo e óxidos de Fe e, provavelmente, Ti. A coloração vermelha e amarelada pode ser decorrente de processos de dissolução da hematita e transformação em goethita, uma vez que as partes amareladas se apresentavam em pequenas cavidades. Maiores quantidades dessas concreções foram observadas nos perfis de encosta e, praticamente, não ocorreram naqueles localizados nos platôs mais baixos e nas áreas abaciadas, indicando processo de desferrificação.

Foram identificados óxidos de Fe e de Ti e caulinitas (Figura 3). A goethita apresentou-se como óxido comum em todos os perfis (com exceção do Argissolo Acinzentado e alguns horizontes dos Espodossolos), sendo identificada por seus picos característicos, referentes aos planos (110) e (130), que se apresentam deslocados em função de sua alta substituição isomórfica por Al (Schulze, 1984). Nos solos com coloração avermelhada foram ainda identificadas a hematita e pequena quantidade de maghemita, inferida pela baixa atração magnética dos concentrados de óxidos de Fe (2-7 m $\left.{ }^{3} \mathrm{~kg} \cdot 10^{-8}\right)$.
$\mathrm{O}$ anatásio $\left(\mathrm{TiO}_{2}\right)$ foi identificado em, praticamente, todos os horizontes dos solos estudados (Figura 3). A melhor definição do pico referente ao plano (101), nos horizontes passíveis de hidromorfismo dos Espodossolos, é função da eluviação e, ou, dissolução das caulinitas, o que minimiza a sobreposição de picos, aumentando sua concentração na fração argila.

Nos horizontes fragipã e Bt dos Espodossolos, foi identificada ainda pequena quantidade de gibbsita $(\mathrm{Gb})$, inferida pela intensidade do pico referente ao plano (002) $(\mathrm{d}=0,480 \mathrm{~nm})$ (Figura 3). Sua confirmação foi realizada em amostras de argilas desferrificadas. A identificação da Gb em fragipã sugere que suas propriedades de dureza e estrutura maciça são dependentes da presença de agentes cimentantes, uma vez que a mineralogia gibbsítica promove maior friabilidade e estruturação ao solo. Resultados semelhantes foram descritos por Moreau (2001).

Não foi identificada a presença de gibbsita nos horizontes não-coesos subsuperficiais dos Argissolos estudados, sugerindo que sua natureza friável devese aos menores conteúdos de argila dispersa condicionados pela presença de óxidos de $\mathrm{Fe}$ (hematita e, ou, goethita). Esses resultados não corroboram os de UFV (1984), que descreve que tal natureza é resultado da desorganização do ajuste face a face da caulinita promovida pela gibbsita, impedindo, assim, a manifestação da coesão.

Portanto, os resultados da mineralogia da fração coloidal sugeriram que o tipo de mineral de argila não constitui fator de diferenciação entre os horizontes coesos e não-coesos, visto que a mineralogia dos solos estudados se mostrou similar.

O pico localizado em $45,35^{\circ} 2 \theta$ (Figura 3) não se correlacionou com nenhum mineral comumente encontrado em solos dos Tabuleiros Costeiros, sendo identificado como griceita (fluoreto de Li). Este mineral foi incluído na discussão apenas a título de registro para investigações futuras, pelo fato de o Li ser agente dispersante, podendo ter algum efeito na dispersão de argila nos solos deste ambiente.

\section{Caracterização micromorfológica por MEV e lâminas delgadas}

$\mathrm{Na}$ análise de micrografias em lâminas delgadas e em agregados (Figuras 4, 5 e 6) foi possível observar que os Argissolos apresentaram feições micromorfológicas de deposição de argilas (argilãs) que esclarecem a origem dos horizontes coesos dos solos estudados da região dos Tabuleiros Costeiros. As maiores variações foram observadas entre os horizontes coesos e nãocoeso, para o mesmo perfil. Um resumo das principais características micromorfológicas é apresentado no quadro 3.

Em geral, o esqueleto mostrou-se composto, quase exclusivamente, de grãos de quartzo com grande variação de tamanho ou, como no caso do fragipã do perfil $\mathrm{PA}_{3}$, maior domínio da fração areia grossa. Os 


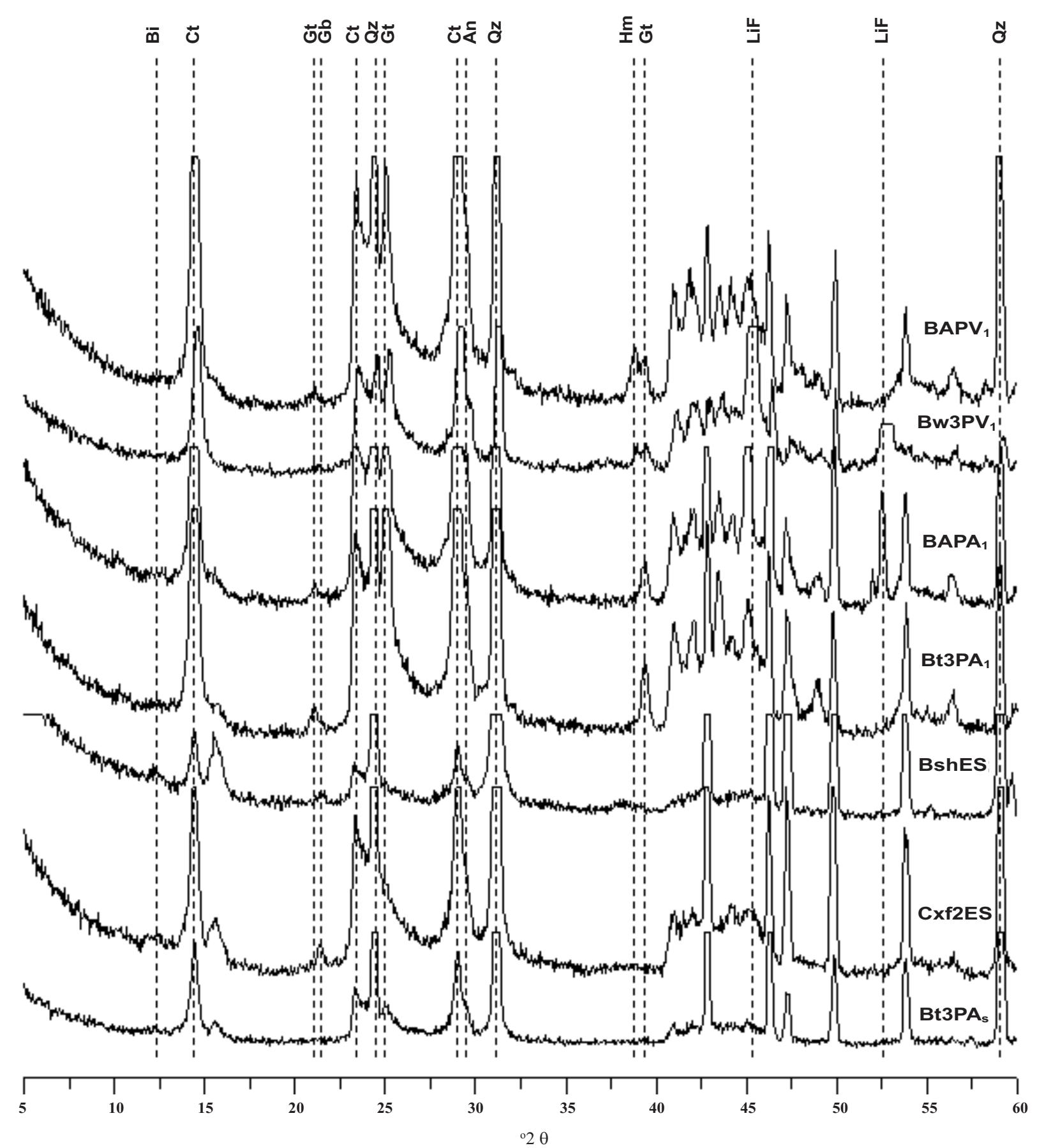

Figura 3. Espectros de difratometria de raios X da TFSA de Argissolo Vermelho, Argissolo Amarelo e Espodossolo. Bi: biotita; Ct: caulinita; Qz: quartzo; An: anatásio; Hm: hematita; Gt: goethita; LiF: griceita.

grãos mostraram-se fissurados, alguns preenchidos por material vermelho de constituição hematítica, e apresentaram graus de esfericidade e de arredondamento variados, sendo estes maiores com a diminuição do tamanho das partículas. De todos os horizontes analisados, o fragipã apresentou os menores graus de esfericidade e de arredondamento, confirmando os resultados das análises realizadas por lupa da fração areia grossa.
Os horizontes coesos apresentaram microfeições semelhantes em todos os perfis estudados, independentemente da cor ou do material de origem. Nestes horizontes, a argila forma um plasma vermelho-escuro $\left(\mathrm{PV}_{1}\right)$ a amarelo $\left(\mathrm{PA}_{5}\right)$ uniformemente distribuído, onde estão inseridas as frações grosseiras. A macroporosidade apresentou valores bem menores que os horizontes subjacentes (Quadro 3) e mostrouse, principalmente, na forma de cavidades pouco 




Figura 4. Fotomicrografias em lâminas delgadas. (a) perfil $\mathrm{PV}_{1}$ horizonte coeso Bt1; (b) perfil PV1 horizonte não-coeso Bt3; (c) perfil $\mathrm{PA}_{1}$ horizonte coeso $\mathrm{Bt1}$; (d) perfil $\mathrm{PA}_{1}$ horizonte não-coeso $\mathrm{Bt3}$; (e) perfil $\mathrm{PA}_{3}$ horizonte 2Cxf2; (f) perfil $\mathrm{PA}_{3}$ horizonte 2Cxf2, detalhe do cútan; (g) perfil $\mathrm{PA}_{5}$ horizonte coeso Bt1; (h) perfil $\mathrm{PA}_{5}$ horizonte não-coeso Bt2 1: quartzo; 2: poros tipo canal; 3: argilãs; 4: fissura; 5: mosqueado plíntico; 6: hematãs.

conectadas e poucos canais e microfissuras não intercomunicados (Figuras 4a,c,g; 5a,c,e). Observouse também, principalmente nos solos vermelhos (conforme descrito no perfil $\mathrm{PV}_{1}$ ), grande quantidade de poros tipo câmaras no interior do plasma macivo ou de agregados, sugerindo estado de degradação. Essa afirmação é corroborada pela presença de microagregação com bordas de coloração mais clara (pequenos domínios), sugerindo que a degradação pode ser decorrente de um processo de desferrificação, promovida, principalmente, pelo clima atual.

A porosidade dos horizontes coesos mostrou-se preenchida por argila iluvial, na forma de argilãs, quebrados ou descontínuos, de cor mais clara que a 
do plasma, com ou sem microlaminação aparente, com moderada a forte anisotropia óptica (Figura 4g), constituindo os caulinitãs/hematãs ou caulinitãs (Brewer, 1976), respectivamente. Em alguns, como no perfil $\mathrm{PA}_{5}$, a microlaminação e a anisotropia apresentaram-se com baixa intensidade, sugerindo que os cútans sejam, mais provavelmente, formados por translocação de argilas dispersas dos agregados circunvizinhos que estão em degradação, sendo definidos aqui como "cútans de difusão" (Figura 4g).
As feições de iluviação em horizontes coesos foram descritas por Melo \& Santos (1996) em Argissolos Amarelos dos Tabuleiros Costeiros de Pernambuco. Esses autores descrevem argilãs nos horizontes Bt1, Bt2 e partes do Bt/Bw e atribuem forte coesão de partes esbranquiçadas dos perfis ao acúmulo de argila iluvial, que preenche a porosidade. Silva et al. (1998), em estudo sobre os Latossolos Amarelos dos Tabuleiros Costeiros do Estado de Alagoas, afirmam que esta pedofeição indica um empobrecimento de argila dos
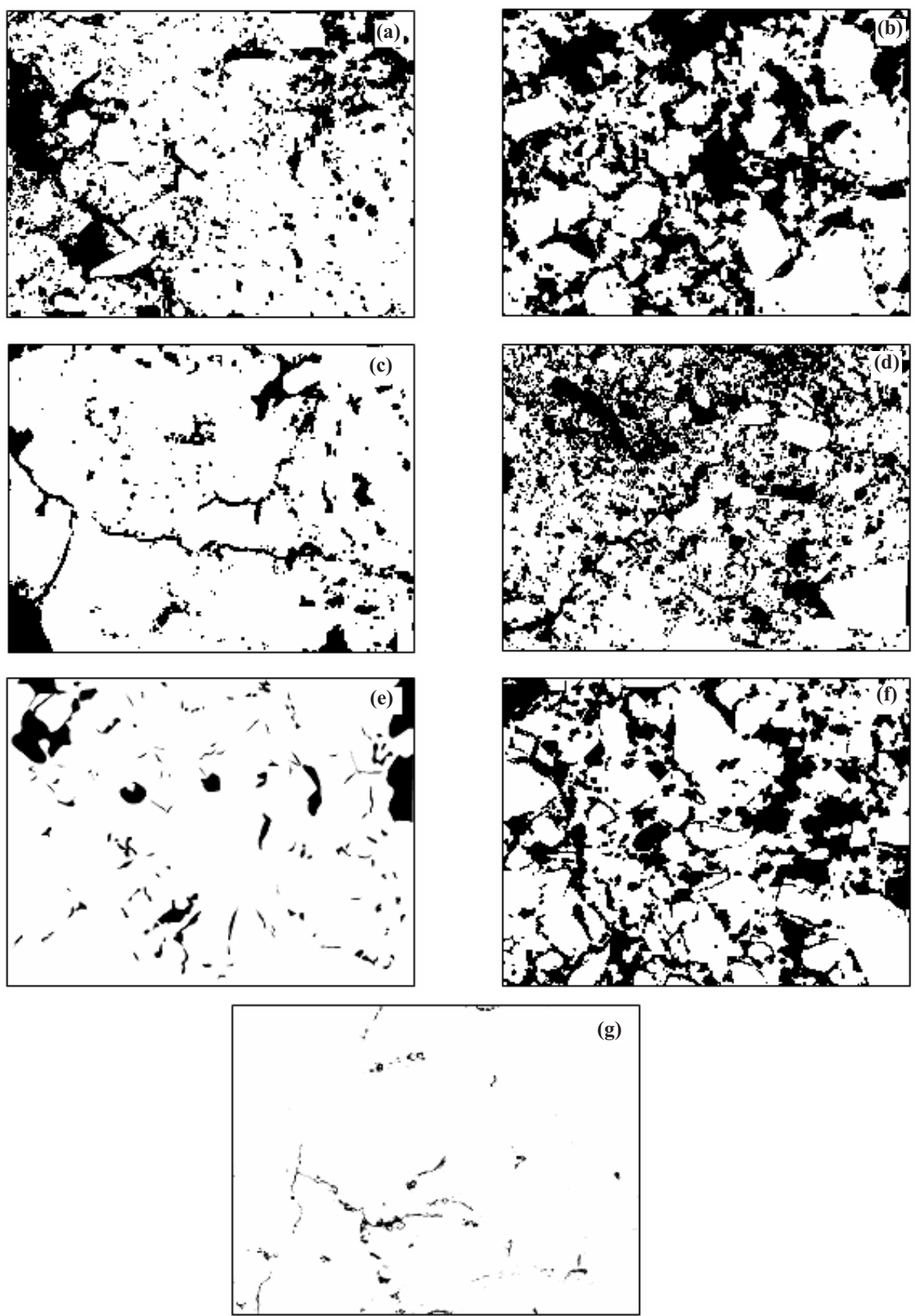

Figura 5. Distribuição dos macroporos. (a) horizonte coeso Bt1 do perfil $\mathrm{PV}_{1}$; (b) horizonte não-coeso Bt3 do perfil $\mathrm{PV}_{1}$; (c) horizonte coeso $\mathrm{Bt1}$ do perfil $\mathrm{PA}_{1}$; (d) horizonte não-coeso $\mathrm{Bt} 3$ do perfil $\mathrm{PA}_{1}$; (e) horizonte coeso $\mathrm{Bt1}$ do perfil $\mathrm{PA}_{5}$; (f) horizonte não-coeso $\mathrm{Bt} 2$ do perfil $\mathrm{PA}_{5}$; (g) fragipã do perfil $\mathrm{PA}_{3}$. 
Quadro 3. Principais características micromorfológicas de alguns solos estudados

\begin{tabular}{|c|c|c|c|c|c|c|c|}
\hline Hor. & Matriz do solo & Microestrutura & Esqueleto & $\begin{array}{l}\text { Macroporos. } \\
\text { calculada }^{(1)}\end{array}$ & $\begin{array}{l}\text { Tipo e forma } \\
\text { dos poros }\end{array}$ & $\begin{array}{c}\text { Feições } \\
\text { de iluviação }\end{array}$ & $\begin{array}{c}\text { Feições } \\
\text { pedológicas }\end{array}$ \\
\hline \multicolumn{8}{|c|}{ Argissolo Vermelho eutrófico $\left(\mathrm{PV}_{1}\right)$} \\
\hline Bt1 & $\begin{array}{l}\text { Isotrópica } \\
\text { vermelha, com } \\
\text { pequenos } \\
\text { domínios } \\
\text { anisotrópicos inter } \\
\text { e intra-agregados }\end{array}$ & $\begin{array}{l}\text { Massiva e parte } \\
\text { microgranular forte e } \\
\text { soldada, com sinais } \\
\text { de degradação. } \\
\text { Bordos mais claros, } \\
\text { sugerindo } \\
\text { desferrificação }\end{array}$ & $\begin{array}{l}\text { Grãos de Qz mal } \\
\text { selecionados e de } \\
\text { tamanho variado, } \\
\text { arestados }(+) \text { e } \\
\text { desarestados, } \\
\text { subalongada a esférica } \\
(+) . \text { Na areia média } \\
\text { domina a forma } \\
\text { subesférica e } \\
\text { desarestada. Concreções } \\
\text { de Fe vermelho escuras }\end{array}$ & $12 \%$ & $\begin{array}{l}\text { Empacotamento } \\
\text { composto. Cavidades } \\
\text { pouco conectadas e } \\
\text { poucos canais e } \\
\text { fissuras. Grande } \\
\text { quantidade de poros } \\
\text { tipo câmaras no } \\
\text { interior do agregado e } \\
\text { plasma }\end{array}$ & $\begin{array}{l}\text { Canais preenchidos por } \\
\text { argilãs, sem } \\
\text { microlamelações e baixa } \\
\text { birrefrigência. Esta sugere } \\
\text { curta translocação da argila, } \\
\text { provavelmente no mesmo } \\
\text { horizonte, sugerindo "cútans } \\
\text { de difusão" }\end{array}$ & $\begin{array}{l}\text { Microagregação } \\
\text { biológica. }\end{array}$ \\
\hline $\mathrm{Bt} 3$ & $\begin{array}{l}\text { Isotrópica } \\
\text { verrmelha }\end{array}$ & $\begin{array}{l}\text { Microgranular } \\
\text { moderada a forte } \\
\text { com poucos } \\
\text { domínios fracamente } \\
\text { coalecida }\end{array}$ & Como acima & $27 \%$ & $\begin{array}{l}\text { Empacotamento } \\
\text { composto. Cavidades } \\
\text { interconectadas por } \\
\text { inúmeros canais }\end{array}$ & ausente & $\begin{array}{l}\text { Microagregação } \\
\text { biológica, canais } \\
\text { biológicos } \\
\text { preenchidos por } \\
\text { pelotas fecais. }\end{array}$ \\
\hline \multicolumn{8}{|c|}{ Argissolo Amarelo eutrófico (PA1) } \\
\hline Bt1 & $\begin{array}{l}\text { Isotrópica e } \\
\text { alaranjada, com } \\
\text { domínios } \\
\text { anisotrópicos } \\
\text { interagregados }\end{array}$ & $\begin{array}{l}\text { Massiva e parte } \\
\text { microgranular fraca e } \\
\text { coalescida, com } \\
\text { sinais de degradação }\end{array}$ & Como acima & $7 \%$ & $\begin{array}{l}\text { Empacotamento } \\
\text { composto, poros mal } \\
\text { conectados, fissuras e } \\
\text { vazios }\end{array}$ & $\begin{array}{l}\text { Canais e câmaras } \\
\text { preenchidos por argila } \\
\text { iluvial. Algumas são } \\
\text { crescentiformes com } \\
\text { microlamelas escuras } \\
\text { (Hematãs). Argilãs inter- } \\
\text { agregados e pápulas } \\
\text { abundantes }\end{array}$ & $\begin{array}{l}\text { Microagregação } \\
\text { biológica, canais } \\
\text { biológicos } \\
\text { preenchidos por } \\
\text { pelotas fecais. }\end{array}$ \\
\hline $\mathrm{Bt} 3$ & $\begin{array}{l}\text { Isotrópica e } \\
\text { alaranjada, com } \\
\text { domínios anisotró- } \\
\text { picos definidos, } \\
\text { relacionados a } \\
\text { pápulas }\end{array}$ & $\begin{array}{l}\text { Microgranular } \\
\text { moderada a forte, } \\
\text { não ou fracamente } \\
\text { coalescida }\end{array}$ & $\begin{array}{l}\text { Como acima, mas com } \\
\text { presença de concreções } \\
\text { de Fe vermelhas e raros } \\
\text { fragm. de carvão }\end{array}$ & $16 \%$ & $\begin{array}{l}\text { Como acima, mas com } \\
\text { maior conectividade }\end{array}$ & $\begin{array}{l}\text { Como acima, mas em menor } \\
\text { quantidade }\end{array}$ & Como acima \\
\hline \multicolumn{8}{|c|}{ Argissolo Amarelo distrófico com fragipã $\left(\mathbf{P A}_{3}\right)$} \\
\hline $2 \mathrm{Cxf} 2$ & $\begin{array}{l}\text { Parcialmente } \\
\text { isotrópica } \\
\text { acinzentada, com } \\
\text { forte anisotropia } \\
\text { nas áreas mais } \\
\text { coalescidas }\end{array}$ & $\begin{array}{l}\text { Massiva e apédica, } \\
\text { fissural; com áreas } \\
\text { microgranular fracas } \\
\text { secundárias, muito } \\
\text { coalescida }\end{array}$ & $\begin{array}{l}\text { Grãos de Qz de tamanho } \\
\text { areia grossa, } \\
\text { predominantemente } \\
\text { arestados. Subalongados } \\
\text { a esféricos }(+) \text {. Na areia } \\
\text { média domina a forma } \\
\text { subesférica }\end{array}$ & $1 \%$ & $\begin{array}{l}\text { Câmaras e canais com } \\
\text { orientação paralela à } \\
\text { superf. Grande } \\
\text { quantidade de fissuras } \\
\text { com distribuição radial } \\
\text { em Qz de tamanho } \\
\text { areia grossa }\end{array}$ & $\begin{array}{l}\text { Grande quantidade de argila } \\
\text { iluvial preenchendo canais e } \\
\text { cavidade, algumas } \\
\text { alternando em caulinitãs } \\
\text { (microlamelações } \\
\text { crescentiformes) e hematãs. } \\
\text { Aqueles de cores vermelhas } \\
\text { mostram-se partidos. } \\
\text { Pápulas abundantes }\end{array}$ & $\begin{array}{l}\text { Poucas pelotas } \\
\text { fecais em canais } \\
\text { com forte } \\
\text { coloração } \\
\text { avermelhada. } \\
\text { Mosqueado de } \\
\text { cor avermelhada } \\
\text { de tamanho } \\
\text { variado } \\
\text { distribuído, } \\
\text { principalmente, } \\
\text { nos bordos dos } \\
\text { canais } \\
\text { (incorporados à } \\
\text { matriz). }\end{array}$ \\
\hline \multicolumn{8}{|c|}{ Argissolo Amarelo distrófico $\left(\mathbf{P A}_{5}\right)$} \\
\hline Bt1 & $\begin{array}{l}\text { Isotrópica com } \\
\text { muitos domínios } \\
\text { anisotrópicos, } \\
\text { principalmente } \\
\text { interagregados }\end{array}$ & $\begin{array}{l}\text { Massiva e parte } \\
\text { microgranular } \\
\text { moderada e } \\
\text { coalescida, com } \\
\text { sinais de degradação }\end{array}$ & $\begin{array}{l}\text { Muitos grãos de Qz de } \\
\text { tamanho areia grossa, } \\
\text { predominantemente } \\
\text { arestados. Subalongados } \\
\text { a esféricos }(+) \text {. Na areia } \\
\text { média domina a forma } \\
\text { subesférica. Concreções } \\
\text { de Fe vermelhas e raros } \\
\text { fragmentados de carvão }\end{array}$ & $8 \%$ & $\begin{array}{l}\text { Empacotamento } \\
\text { composto, poros mal } \\
\text { conectados, fissuras e } \\
\text { vazios }\end{array}$ & $\begin{array}{l}\text { Muitos argilãs } \\
\text { interagregados de cor mais } \\
\text { clara que a do plasma, com } \\
\text { poucas microlamelações } \\
\text { escuras e moderada } \\
\text { birrefringência }\end{array}$ & $\begin{array}{l}\text { Microagregação } \\
\text { térmita, poucos } \\
\text { canais biológicos } \\
\text { e pelotas fecais. }\end{array}$ \\
\hline Bt2 & $\begin{array}{l}\text { Isotrópica, com } \\
\text { fraca anisotropia } \\
\text { intergranular }\end{array}$ & $\begin{array}{l}\text { Microgranular } \\
\text { moderada a forte, } \\
\text { não ou fracamente } \\
\text { coalescida }\end{array}$ & Como acima & $32 \%$ & $\begin{array}{l}\text { Empacotamento } \\
\text { composto. Cavidades } \\
\text { interconectadas por } \\
\text { inúmeros canais }\end{array}$ & $\begin{array}{l}\text { Poucos argilãs menores que } \\
\text { o anterior e interagregados } \\
\text { de cor mais clara que a do } \\
\text { plasma, sem } \\
\text { microlamelações e moderada } \\
\text { birrefringência }\end{array}$ & $\begin{array}{l}\text { Microagregação } \\
\text { térmita, canais } \\
\text { biológicos e } \\
\text { abundantes } \\
\text { pelotas fecais. }\end{array}$ \\
\hline
\end{tabular}

(1) Calculada por meio do uso do software SOLICON (média de três repetições); (+) maior quantidade; Qz: quartzo. 
horizontes superficiais e possível formação de um horizonte B textural com o tempo, como conseqüência dessa iluviação de argila acelerada pelo cultivo (arenização superficial). Contudo, o presente trabalho é pioneiro em constatar tal feição, além do caráter coeso, em solos com matiz vermelho.

Para os horizontes mais subsuperficiais dos Argissolos, sem o caráter coeso, foram observados matizes semelhantes aos dos horizontes coesos (Quadro 3), distinto desenvolvimento microestrutural e ausência ou quantidade bem menor de feições de iluviação de argila (argilãs). A estrutura mostrou-se predominantemente microgranular moderada a bem desenvolvida, conferindo maiores porosidade e friabilidade ao horizonte. Os poros apresentaram-se como cavidades, bem como grande quantidade de canais intergranulares interconectados (Figura 5b,d,f).

As feições de deposição de argila (cútans) descritas nos horizontes coesos corroboram os dados físicos de argiluviação de argilas finas e muito finas dos
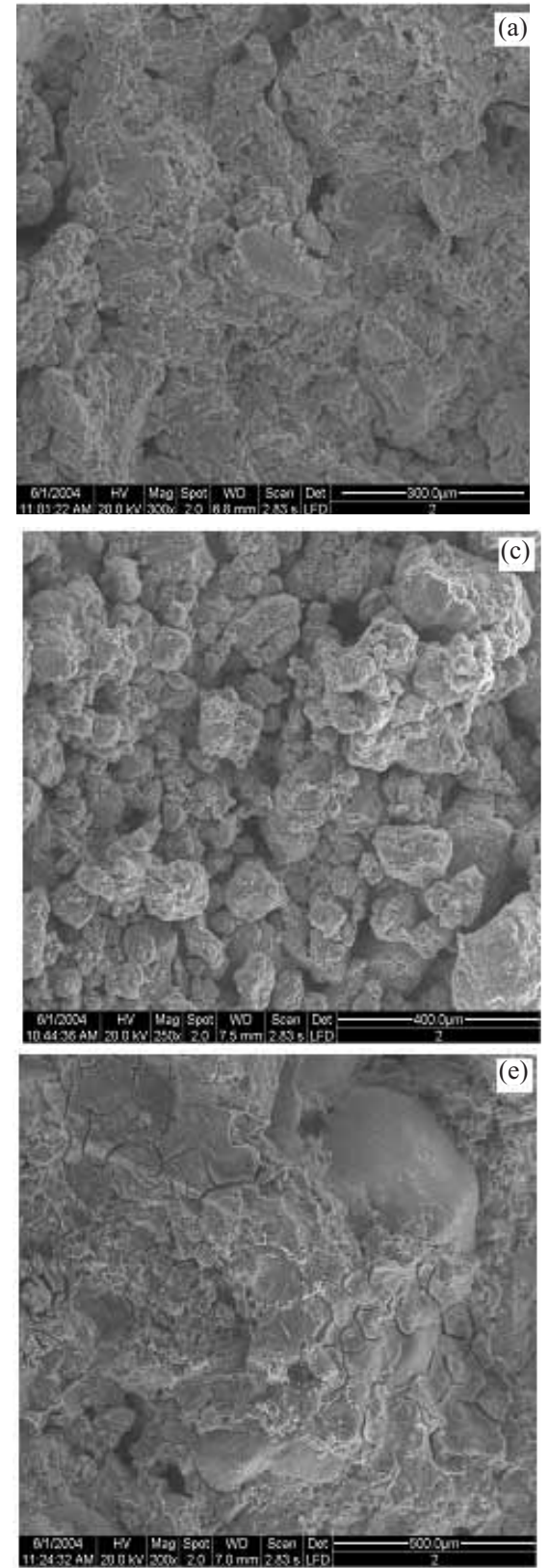
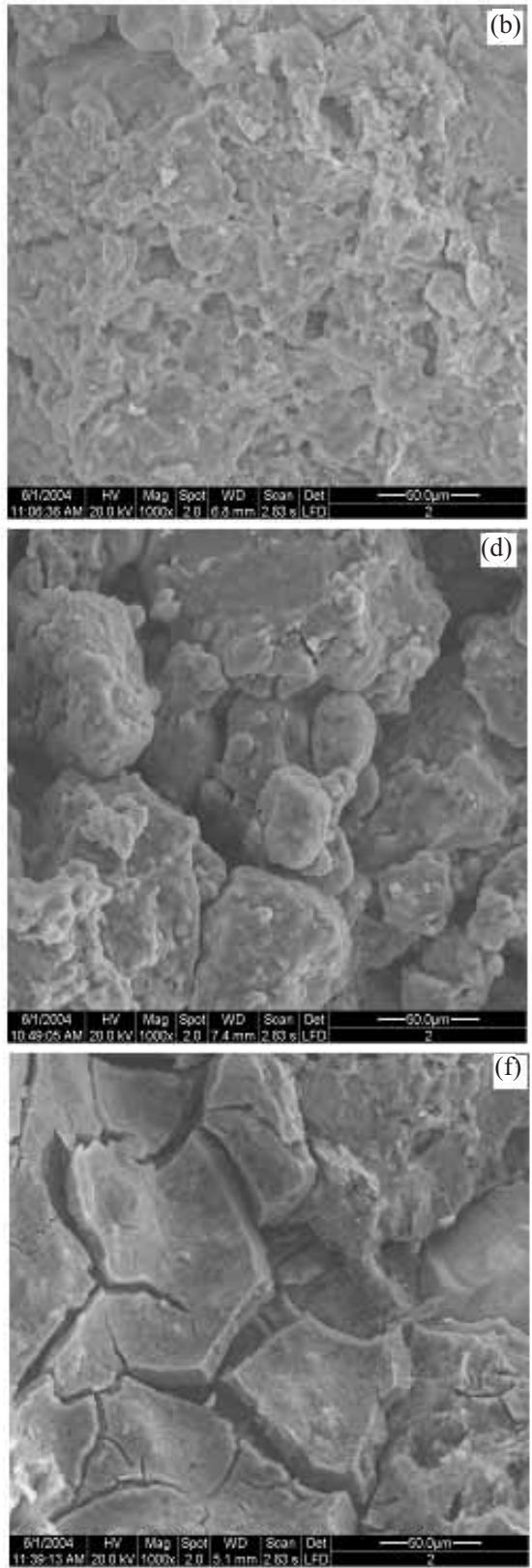

Figura 6. Fotomicrografias em agregados indeformados por MEV: (a) organização estrutural do perfil PV 1 horizonte coeso Bt1; (b) detalhe do plasma argiloso disposto na forma de lâmelas da imagem "a"; (c) estruturação do perfil $\mathrm{PV}_{1}$ horizonte não-coeso Bt3; (d) detalhe da estrutura microgranular da imagem “c"; (e) organização estrutural do fragipã do perfil $\mathbf{P A}_{3}$, mostrando plasma argiloso depositado nas paredes dos poros; (f) detalhe da imagem " $e$ ". 
horizontes superficiais, com posterior preenchimento de poros nos horizonte subseqüentes (BA e, ou, Bt1). Dessa forma, os resultados do presente trabalho demonstram que a coesão é conseqüência de um processo físico, descartando-se, assim, a hipótese de cimentação branda por géis de $\mathrm{Si}$, proposta por Meireles \& Ribeiro (1995).

Para o fragipã do perfil $\mathrm{PA}_{3}$, observou-se plasma mais denso e contínuo, com coloração mais próxima do bruno-amarelado (Figura 4e). Os espaços vazios são, basicamente, poros tipo câmaras, canais paralelos à superfície e microfissura com distribuição radial em quartzos mais grosseiros (Figuras 4e e 5g). Grande parte dessa porosidade apresenta-se preenchida por argila iluvial, variando em cor e espessura, sendo a característica pedológica mais marcante deste horizonte. Aqueles de coloração mais bruno-amarelada sempre mostram microlamelas crescentiformes, sendo provavelmente compostos por caulinitas (caulinitãs) e mais espessos. Os demais apresentam coloração vermelha, de composição principalmente hematítica (hematitãs), sem microlamelações, delgados e presentes, principalmente, nas bordas dos canais (Figura 4f). Alguns deles ocorrem na microporosidade, entre o plasma e o esqueleto quartzoso.

No horizonte fragipã foi observada também a ocorrência de manchas de coloração vermelha, distribuídas por todo o plasma, mas, principalmente, concentradas nas bordas dos canais mais espessos. Aquelas que se mostram embebidas pelo plasma apresentaram forma bastante esférica, destacadas, provavelmente endurecidas, constituindo distintas manchas plínticas (Figura 4e,f).

A microestruturação e as feições de iluviação dos solos foram também observadas por microscopia eletrônica de varredura (MEV) em agregados indeformados (Figura 6). O exame dos horizontes coesos demonstrou a presença de grande quantidade de plasma argiloso, preenchendo os espaços intergranulares, dispostos na forma de estruturas laminares, formando os cútans de deposição (Figura 6a,b). Em razão de forte correlação entre argila dispersa em água e argila fina, especula-se que esta pedofeição de iluviação seja composta, sobretudo, por caulinitas menores de $0,2 \mu \mathrm{m}$.

Em quantidade muito pequena, nos horizontes coesos, também foram identificadas pequenas estrias na superfície de alguns agregados, denominados de micro-slickensides. Essa feição pode ser reflexo da ocorrência de ciclos de umedecimento e secagem nos horizontes superficiais, que, de alguma maneira, podem contribuir para a gênese da coesão, seja orientando as partículas de caulinita face a face (UFV, 1984), seja promovendo colapso estrutural e, conseqüentemente, maior teor de argila dispersa em água.

As micrografias de MEV dos horizontes não-coesos revelaram feições distintas do horizonte, anteriormente discutido, corroborando os resultados da análise de seções finas. Foi observada forte estruturação microgranular, com diâmetros variáveis e alta porosidade interagregados, principalmente na forma de canais com diâmetro de até $100 \mu \mathrm{m}$ (Figura 6c,d).

O exame do fragipã, da mesma forma da seção fina, revelou grande quantidade de material argiloso depositado na parede dos poros, na forma de argilãs. Estes se apresentaram bastante fissurados, com fissuras de espessura aproximada de $15 \mu \mathrm{m}$ (Figura 6e,f). Mesma feição foi identificada por Filizola et al. (2001), em fragipãs e duripãs dos Tabuleiros Costeiros de Pernambuco e Alagoas. Por meio de microanálises, esses autores afirmam que esses cútans apresentam composição variável, variando de caulinítico a géis aluminosos, passando por géis aluminossilicosos, podendo apresentar teores elevados de $\mathrm{Fe}$, principalmente nas bordas dos poros. Esses resultados corroboram a descrição anteriormente realizada em seções finas, com base no exame da cor, forma e polarização.

\section{CONCLUSÕES}

1. Os resultados das análises físicas e micromorfológicas sugerem que a gênese dos horizontes coesos deve-se ao maior conteúdo de argilas muito finas, menores que $0,2 \mu \mathrm{m}$, translocadas entre horizontes ou dentro do mesmo horizonte na forma de argila dispersa.

2. As características micromorfológicas corroboram o fato de que os horizontes coesos são derivados da acumulação de argila fina iluvial, uma vez que foi identificada grande quantidade de feições de iluviação com e sem microlamelações, moderada a alta birrefringência e composição caulinítica.

3. A maior coesão observada para o Argissolo Amarelo localizado em clima mais seco, em relação àqueles de clima mais úmido, pode ser devido à sua granulometria menos argilosa e à maior quantidade de feições de iluviação de argila.

4 A presença de gibbsita no fragipã sugere que sua formação se deve à cimentação química, intensificada pela iluviação de argilas finas e conseqüente entupimento de sua porosidade.

\section{AGRADECIMENTOS}

À CAPES e CNPq, pelo apoio financeiro e bolsa de doutoramento "sandwich". A Aracruz Celulose, pelo apoio aos trabalhos de coleta de solos, especialmente aos doutores Sebastião Fonseca e Sebastião Andrade.

\section{LITERATURA CITADA}

ACHÁ-PANOSO, L. Latossolo Vermelho-Amarelo de "Tabuleiro" do Espírito Santo: Formação, características e classificação. Recife, Universidade Federal Rural de Pernambuco, 1976. 116p. (Tese de Livre Docência) 
ANDRADE, F.V.; MENDONÇA, E.S.; CORRÊA, M.M. \& SCHAEFER, C.E.R.G. Efeito dos ácidos orgânicos de baixo peso molecular na desestabilização estrutural e formação de camadas coesas. In: ENCONTRO BRASILEIRO DE SUBSTÂNCIAS HÚMICAS, 5., Recife, 2003. Anais. Recife, Universidade Federal Rural de Pernambuco, 2003. CD-ROM.

ANJOS, L.H.C. Caracterização, gênese, classificação e aptidão agrícola de uma seqüência de solos do Terciário na região de Campos-RJ. Itaguaí, Universidade Federal Rural do Rio de Janeiro, 1985. 194p. (Tese de Mestrado)

BARZEGAR, R.; RENGASAMY, P. \& OADES, M. Effects of clays type and rate of wetting on the mellowing of compacted soils. Geoderma, 68:39-49, 1995.

BRASIL. MINISTÉRIO DA AGRICULTURA - DNPA/DPP. Levantamento Exploratório/reconhecimento de solos do Estado de Pernambuco. Recife, 1972. 2v. (DNPEA. Boletim Técnico 26; SUDENE-DRN. Série Pedologia, 14)

BRASIL. MINISTÉRIO DAS MINAS E ENERGIA - Secretaria Geral. Pedologia. Folhas SF.23/24-Rio de Janeiro/Vitória. Projeto RADAMBRASIL, 1983. p.385-552. (Levantamento de Recursos Naturais, v.32)

BREWER, R. Fabric and mineral analysis of soils. New York, Robert Krieger Publishing Company, 1976. 482p.

DEPARTAMENTO NACIONAL DE PRODUÇÃO MINERAL DNPM. Geologia do Brasil. Texto explicativo do mapa geológico do Brasil e da área oceânico adjacente, incluindo depósitos minerais. Brasília, 1984. 501p.

EMPRESA BRASILEIRA DE PESQUISA AGROPECUÁRIA EMBRAPA. Centro Nacional de Pesquisa de Solos. Manual de métodos de análise de solo. 2.ed. Rio de Janeiro, 1997. $212 \mathrm{p}$

EMPRESA BRASILEIRA DE PESQUISA AGROPECUÁRIA EMBRAPA. Centro Nacional de Pesquisa de Solos. Sistema brasileiro de classificação de solos. Brasília, 1999. $412 \mathrm{p}$.

EMPRESA BRASILEIRA DE PESQUISA AGROPECUÁRIA EMBRAPA. Centro Nacional de Pesquisa de Solos. REUNIÃO DE CLASSIFICAÇÃO, CORRELAÇÃO E APLICAÇÃO DE LEVANTAMENTO DE SOLOS, 4., Rio de Janeiro, 1995. Anais. Rio de Janeiro, Embrapa, SNLCS/ SBCS, 1995. 157p.

EMPRESA BRASILEIRA DE PESQUISA AGROPECUÁRIA EMBRAPA. Serviço Nacional de Levantamento e Conservação de Solos. Levantamento exploratórioreconhecimento de solos da margem direita do rio São Francisco; Estado da Bahia. Recife, Embrapa-SNLCS/ SUDENE-DRN, 1977. 737p. (Boletim Técnico, 52)

EMPRESA BRASILEIRA DE PESQUISA AGROPECUÁRIA EMBRAPA. Serviço Nacional de Levantamento e Conservação de Solos. Levantamento exploratórioreconhecimento de solos do Espírito Santo. Rio de Janeiro, 1978. 461p. (Boletim Técnico, 45)
FERREIRA, M.M. Influência da mineralogia da fração argila nas propriedades físicas de Latossolos brasileiros. Viçosa, MG, Universidade Federal de Viçosa, 1988. 79p. (Tese de Doutorado)

FILIZOLA, H.F.; LAMOTTE, M.; FRITSCH, E.; BOULET, R.; ARAÚJO FILHO, J.C.; SILVA, F.B.R. \& LEPRUN, J.C. Os fragipãs e duripãs das depressões dos Tabuleiros Costeiros do Nordeste brasileiro. R. Bras. Ci. Solo, 25:947964, 2001.

FITZPATRICK, E.A. Microscopy and micromorphology of soils. Chichester, John Wiley, 1993. 304p.

FONSECA, O.O.M. Caracterização e classificação de solos Latossólicos e Podzólicos desenvolvidos nos sedimentos do Terciário no litoral brasileiro. Itaguaí, Universidade Federal Rural do Rio de Janeiro, 1986. 185p. (Tese de Mestrado)

JACKSON, M.L. Soil chemical analysis advanced course. Madison, University of Wisconsin, 1969.

JACOMINE, P.K.T. Distribuição geográfica, características e classificação dos solos coesos dos Tabuleiros Costeiros. In: REUNIÃO TÉCNICA SOBRE SOLOS COESOS DOS TABULEIROS COSTEIROS, Cruz das Almas, 1996. Anais. Aracaju, Embrapa, CPATC; CNPMF; IGUFBA, 1996. p.1326.

LAMOTTE, M.; BRAUND, A.; HUMBEL, F.X.; HERBILLON, A.J. \& RIEU, M. A hard sandy-loam soil from semi-arid northern Cameroon: Fabric of the groundmass. Eur. J. Soil Sci., 48:213-225, 1997a.

LAMOTTE, M.; BRAUND, A.; OHNENSTETTER, D.; ILDEFONSE, P. \& PÉDRO, G. A hard sandy-loam soil from semi-arid northern Cameroon: Geochemistry and mineralogy of the bonding agent. Eur. J. Soil Sci., 48:227237, 1997b.

LEMOS, R.C. \& SANTOS, R.D. Manual de descrição e coleta de solo no campo. Rio de Janeiro, Embrapa/CNPS/SBCS, 1996. $45 \mathrm{p}$

MEIRELES, M.C.S. \& RIBEIRO, L.P. Caracterização da sílica em horizontes coesos de solos de tabuleiros. In: CONGRESSO BRASILEIRO DE CIÊNCIA DO SOLO, 25., Viçosa, 1995. Resumos expandidos...Viçosa, MG, Sociedade Brasileira de Ciência do Solo, Universidade Federal de Viçosa, 1995. p.1688-1689.

MELO, E.J.R.. \& SANTOS, M.C. Micromorfologia e mineralogia de dois solos de tabuleiro costeiro de Pernambuco. R. Bras. Ci. Solo, 20:99-108, 1996.

MOREAU, A.M.S.S. Gênese, química e micromorfologia de horizontes coeso, fragipã e duripã em solos do tabuleiro costeiro no sul da Bahia. Viçosa, MG, Universidade Federal de Viçosa, 2001. 139p. (Tese de Doutorado)

OLIVEIRA, L.B. \& MELO, V. Caracterização físico-hídrica do solo. I. Unidade Itapirema. Pesq. Agropec. Bras., 5:35-48, 1970.

OLIVEIRA, L.B.; DANTAS, H.S.; CAMPELO, A.B.; GALVÃO, S.J. \& GOMES, I.F. Caracterização de adensamento no subsolo de uma área de tabuleiro da Estação Experimental do Curado, Recife. Pesq. Agropec. Bras., 3:207-214, 1968. 
PETERSEN, G.W.; RANNEY, R.W.; CUNNINGHAM, R.L. \& MATELSKI, R.P. Fragipans in Pennsylvania soils: A statistical study of laboratory data. Soil Sci. Soc. Am. Proc., 34:719-722, 1970.

QUIRK, J.P. Significance of surface areas calculated from water vapor sorption isotherms by use of the B.E.T. equation. Soil Sci., 80:423-430, 1955.

RIBEIRO, L.P. Os Latossolos Amarelos do Recôncavo Baiano: Gênese, evolução e degradação. Salvador, SEPLANTEC/ CADCT, 1998. 99p.

RICHIE, A.; WILDING, L.P.; HALL, G.F. \& STAHNKE, C.R. Genetic implications of B horizons in Aqualfs of Northeastern Ohio. Soil Sci. Soc. Am. J., 38:351-358, 1974.

SCHULZE, D.G. The influence of aluminum on iron oxides. VIII. Unit-cell dimensions of Al-substituted goethites and estimation of $\mathrm{Al}$ from them. Clays Clay Miner., 32:36-44, 1984.

SCHWERTMANN, U. \& CARLSON, L. Aluminum influence on iron oxides: XVII. Unit-cell parameters and aluminum substitution of natural goethites. Soil Sci. Soc. Am. J., 58:256-261, 1994.

SHANMUGANATHAN, R.T. \& OADES, J.M. Influence of anions on dispersion and physical properties of the A horizon of a red-brown-earth. Geoderma, 29:257-277, 1983.

SILVA, A.J.N. \& RIBEIRO, M.R. Caracterização de Latossolo Amarelo sob cultivo contínuo de cana-de-açúcar no Estado de Alagoas: Propriedades químicas. R. Bras. Ci. Solo, 22:291-299, 1998.
SILVA, A.J.N.; RIBEIRO, M.R.; MERMUT, A.R. \& BENKE, M.B. Influência do cultivo contínuo da cana-de-açúcar em Latossolos Amarelos coesos do Estado de Alagoas: Propriedades micromorfológicas. R. Bras. Ci. Solo, 22:515525, 1998 .

SILVA, J.M.R.; LIMA, M.I.C.; VERONESE, V.F.; RIBEIRO JÚNIOR, R.N.; ROCHA, R.M. \& SIGA JUNIOR, O. Secretaria de Planejamento e Coordenação da Presidência da República - Fundação Instituto Brasileiro de Geografia e Estatística - IBGE. Geologia. Folha SE.24 Rio Doce. Rio de Janeiro, 1987. p.23-172. (Levantamento de Recursos Naturais, v.34)

SIQUEIRA, J.D.P.; LISBOA, R.S.; FERREIRA, A.M.; SOUZA, M.F.R.; ARAÚJO, E.; LISBÃO JÚNIO, L. \& SIQUEIRA, M.M. Estudo ambiental para os programas de fomento florestal da Aracruz Celulose S.A. e extensão florestal do Governo do Estado do Espírito Santo. Floresta, Edição Especial:3-67, 2004.

TAZAKI, K.; KIMURA, S.; YOSHIMURA, T.; AKAI, J. \& FYFE, W.S. Clays-organic complexes as a cementing agent in the Arahama sand dune, Japan. Clays Clay Miner., 37:219-226, 1989.

UNIVERSIDADEDE FEDERAL DE VIÇOSA - UFV. Caracterização de solos e avaliação dos principais sistemas de manejo dos Tabuleiros Costeiros do Baixo Rio Doce e das regiões Norte do Estado do Espírito Santo e sua interpretação para uso agrícola. Viçosa, MG, 1984. 153p.

YOEMANS, J.C. \& BREMNER, J.M. A rapid and precise method for routine determination of organic carbon in soil. Comm. Soil Sci. Plant Anal., 19:1467-1476, 1988. 